\title{
Análise da ventilação natural conforme planos diretores: resultados de pesquisa em Belém, PA
}

Analysis of natural ventilation according to master plans: research results in Belem, PA

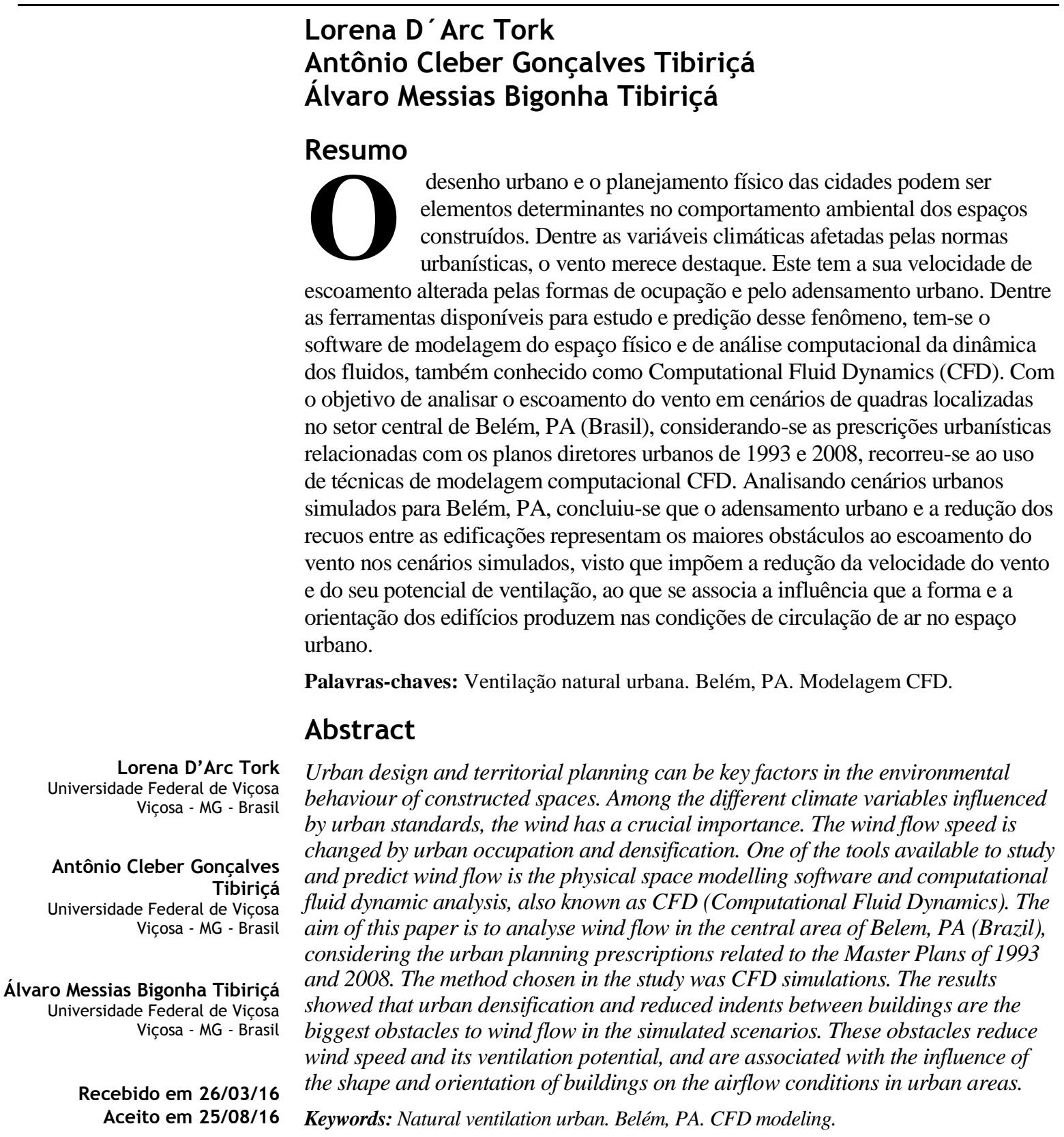

TORK, L. D.; TIBIRIÇÁ, A. C. G.; TIBIRIÇÁ,Á. M. B. Análise da ventilação natural conforme planos diretores: 


\section{Introdução}

O desenho urbano e o planejamento, ao regulamentarem aspectos urbanísticos, definem questões físicas, legais e jurídicas que têm desdobramentos nas diretrizes construtivas para as edificações e nas condições ambientais arquitetônico-urbanísticas, com repercussões na qualidade do ambiente citadino e no conforto térmico.

Para Asfour (2010) e Al-Sallal e Al-Rais (2012), a ventilação natural é considerada a principal estratégia bioclimática passiva para se alcançar o conforto térmico em meio arquitetônico, para clima quente e úmido. Corbella e Yannas (2009) afirmam que o adensamento das áreas urbanas são algumas das alterações que podem interferir significativamente na velocidade, intensidade $\mathrm{e}$ sentido do vento em meio urbano, e alterar o microclima local. Nesse caso, a velocidade de escoamento do ar e os efeitos do vento no entorno das edificações são modificados pelas formas de ocupação e pelo adensamento urbano. Em função da velocidade do vento, é possível obter renovação de ar, alterar cargas térmicas e promover ventilação cruzada nas edificações. Pelos coeficientes de pressão, tem-se a possibilidade de estimar o potencial de vazões internas entre fachadas de edificações.

Nesse campo em particular, o interesse do artigo se volta para o município de Belém, PA, por ser uma cidade de grande porte e com legislação urbana consolidada, na qual se entende que há oportunidade para desenvolver estudos da evolução e prospecção desse fenômeno urbano (Figura 1). Tal interesse se ressalta no sentido de melhor compreender as repercussões das intervenções humanas no meio natural, provocando modificações que implicam a troca da composição superficial de massa vegetada por massa edificada, impondo alterações nas propriedades superficiais e na dinâmica do escoamento das massas de ar, fato que é mais característico quando os processos de urbanização passam a admitir maiores densidades de ocupação.

O Plano Diretor Municipal, instrumento de Política Urbana previsto no Estatuto da Cidade (BRASIL, 2001) indutor do desenvolvimento urbano, requer no seu cumprimento atenções, principalmente quanto ao uso e ocupação do solo com edificações de maior porte, situação que se mostra mais presente quando o adensamento urbano tende a produzir a sensação de perda de privacidade, inclusive da visão do céu e do sol e da ventilação e luz naturais. Nesse sentido, um objeto de manifestação das pessoas em Belém, PA, é quanto a alterações relacionadas com a circulação de ar no meio urbano, campo de interesse deste artigo sob a seguinte questão: como o uso e a ocupação do solo urbano e a verticalização podem estar induzindo mudanças no comportamento dos ventos num setor da região central da cidade?

\section{Figura 1 - Localização de Belém, PA}

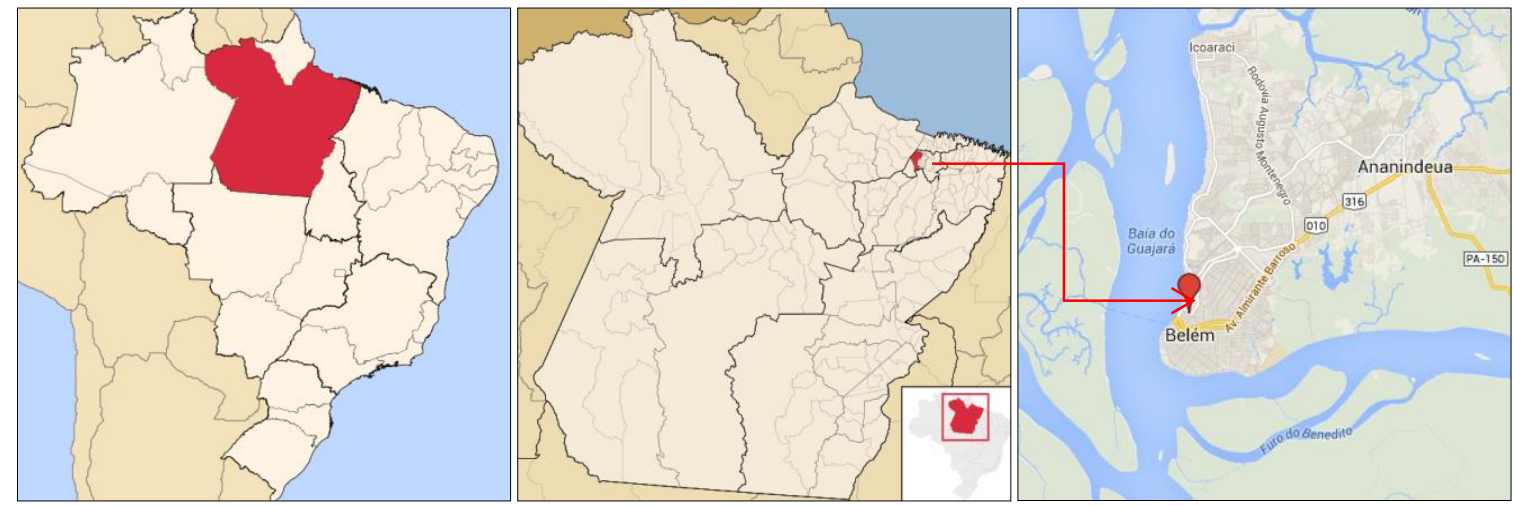

Fonte: Wilipedia (2014). 
Na busca de respostas para esse caso, fenômenos relacionados ao escoamento do ar em meio urbano tornaram-se objeto de investigação de diversas pesquisas. Como ferramentas disponíveis para estudo e predição desse fenômeno, tem-se o software de modelagem do espaço físico e de análise computacional da dinâmica dos fluidos, conhecido como CFD (CÓSTOLA; ALUCCI, 2011). Importantes pesquisas sobre o escoamento do vento em ambientes urbanos com auxílio das técnicas CFD podem ser citadas, como os trabalhos de Prata (2005), Leite (2009), Asfour (2010), Reiter (2010), Al-Sallal e Al-Rais (2012). Entre os assuntos levantados nessas pesquisas, destacam-se questões voltadas às alterações como: escoamento do vento em nível de pedestre pela verticalização urbana; influência dos padrões de ocupação do solo sobre a ventilação natural; efeito da disposição de edifícios no potencial de ventilação urbana; arrefecimento passivo para clima quente úmido através do vento.

Sendo assim, este artigo tem por objetivo analisar o impacto das prescrições urbanísticas sob a vigência dos planos diretores urbanos de 1993 e 2008 no escoamento do vento em cenários de quadras localizadas no setor central de Belém, PA.

\section{Metodologia}

Os procedimentos metodológicos utilizados foram divididos em quatro etapas:

(a) seleção da quadra e cenários simulados;

(b) caracterização do vento em Belém;

(c) simulação computacional com CFD; e

(d) análise dos resultados.

\section{Seleção da quadra e cenários simulados}

A escolha da área de estudo foi a Zona Ambiental Urbana 6 (ZAU), Setor 1, localizada na região central de Belém (Quadro 1, etapa 2). Essa escolha foi definida mediante análise do Plano Diretor de Belém (BELÉM, 2008) e se justifica por este incentivar o remembramento e a criação de novos arranjos de edificações, que possibilita a verticalização. Após a escolha da zona e do setor que seriam investigados, partiu-se para a definição de quais quadras seriam objeto de estudo. A seleção foi feita em função de um plano de amostragem por conglomerado, realizado em cinco etapas (Quadro 1).

\section{Criação dos cenários de verticalização: retrospectivo, atual e prospectivo}

A próxima etapa foi a construção dos cenários de verticalização. Considerou-se, ainda, um período de até cinco anos a partir da entrada em vigor dessas leis, tempo normalmente necessário para as adaptações do mercado às legislações urbanísticas.

Foram elaborados três cenários para a quadra selecionada, cada um correspondente a um período de tempo em função dos planos diretores urbanos de 1993 e 2008 e que influenciaram o período de abrangência do estudo. Assim, construíram-se três cenários:

(a) cenário retrospectivo (vigência do Plano Diretor de 1993): recorreu-se ao levantamento de informações dos lotes na Companhia de Desenvolvimento e Administração da Área Metropolitana de Belém (Codem). Os dados levantados corresponderam às informações descritivas de cada imóvel (tipo de uso do imóvel, área do terreno, profundidade, testada do lote, número de pavimentos e croqui com medidas das edificações) no ano 2000. Essas informações foram transcritas para um arquivo digital (Figura 2a);

(b) cenário atual (referente ao Plano Diretor de 2008): desenvolvido a partir do levantamento da quadra retrospectiva, foi atualizado pelo levantamento fotográfico da fachada de cada lote da quadra, e imagens do Google Maps (2014). Essas informações foram cruzadas com os arquivos digitais gerados no cenário retrospectivo e atualizadas com as informações fotográficas atuais de cada lote (Figura 2b); e

(c) cenário prospectivo (corresponde a um cenário possível em 2023, caso o Plano Diretor de 2008 continue em vigor): foram observados quais lotes estavam inutilizados. Por imagens de satélite foram identificados os lotes passíveis de remembramento, como edificações de uso habitacional com até dois pavimentos. Para realizar o remembramento, estabeleceu-se um modelo padrão de edifícios residenciais encontrados na região central de Belém com as seguintes características: unidades autônomas de $72 \mathrm{~m}^{2}$, com sala, dois dormitórios, área de serviço, banheiro e cozinha. Tendo-se definido o edifíciopadrão, simulou-se a aplicação deste nos lotes remembrados. Foi aplicado o coeficiente máximo permitido pela legislação de 2008, desconsiderando instrumentos urbanísticos como outorga onerosa. Dessa forma, criou-se um cenário com a ocupação máxima permitida pela lei e as possíveis edificações que surgirão num prazo de até 15 anos (Figura 2c). 
Quadro 1 - Etapas para seleção da quadra simulada

\begin{tabular}{|c|c|}
\hline \multicolumn{2}{|c|}{ Etapa 1 (Zonas) } \\
\hline \multicolumn{2}{|c|}{$\begin{array}{l}\text { Etapa } 1 \text { (Zonas) } \\
\text { 1. Separação da ZAU 6 - Setor 1 nas categorias zona limítrofe (ZL) e zona interna (ZI), e análise de } \\
\text { imagens do Google Maps (2014); 2. Observação das condições de incentivo a adensamento e infraestrutura } \\
\text { na ZL e ZI. }\end{array}$} \\
\hline $\begin{array}{ll}\text { Etapa 2 } \\
\end{array}$ & Etapa 3 \\
\hline $\begin{array}{l}\text { Subdividiu-se a ZL e a ZI em subzonas, sendo três } \\
\text { ZLs (Z1L, Z2L e Z3L) - aproximadamente 30\% da } \\
\text { ZAU } 6 \text {-, e quatro ZIs (Z1IN, Z2IN, Z3IN e Z4IN) } \\
\text { - os outros 70\%. }\end{array}$ & $\begin{array}{l}\text { 1. Sorteio da primeira subzona; } 2 \text {. Sorteio de uma } \\
\text { quadra da primeira subzona; } 3 \text {. Aplicação de um } \\
\text { buffer de } 400 \mathrm{~m} \text { em relação ao perímetro da quadra } \\
\text { sorteada. }\end{array}$ \\
\hline 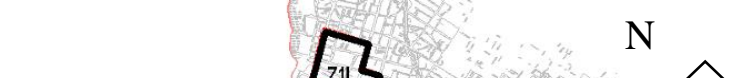 & N \\
\hline Etapa 4 & Etapa 5 \\
\hline $\begin{array}{l}\text { Sorteio de duas ZLs e três ZIs, definindo-se cinco } \\
\text { quadras. }\end{array}$ & $\begin{array}{l}\text { Quadra sorteada para simulação: Z2IN, no bairro } \\
\text { São Braz. }\end{array}$ \\
\hline $\mathrm{N}$ & N \\
\hline Quadra simulada & Google Maps (2014) \\
\hline (1) & 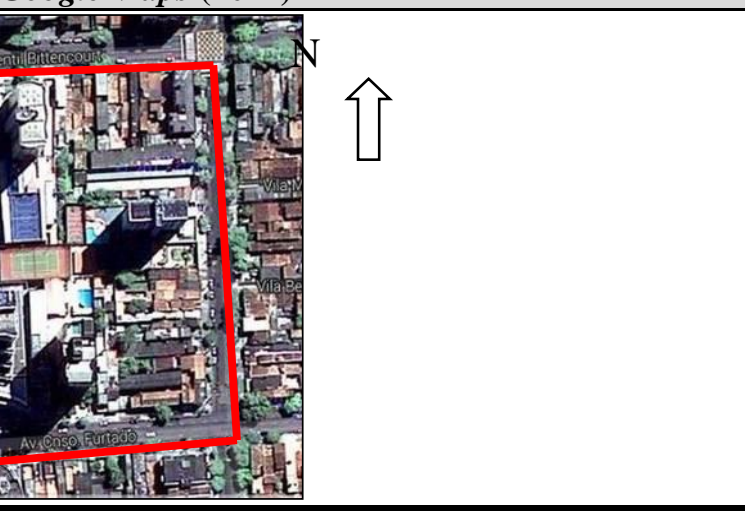 \\
\hline
\end{tabular}


Figura 2 - Cenários verticalizados em função dos planos diretores para a quadra selecionada

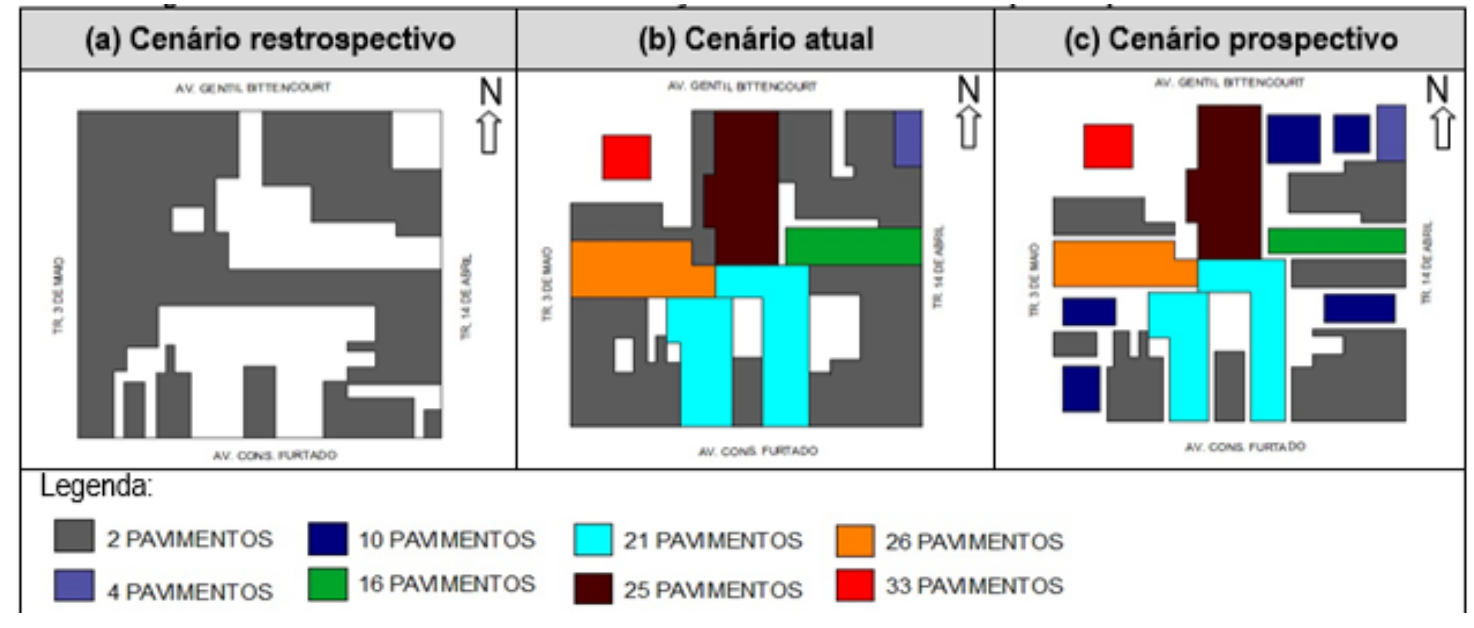

\section{Caracterização do vento em Belém}

Belém situa-se na parte setentrional da Amazônia e está localizada às margens da Baía do Guajará, na confluência com o Rio Guamá, e a $120 \mathrm{~km}$ do Oceano Atlântico pela Baía do Marajó. Tem como referências geográficas as coordenadas $1^{\circ} 23^{\prime} \mathrm{S}$ e $48^{\circ} 29^{\prime} \mathrm{W}$, com $16 \mathrm{~m}$ de altitude em relação ao nível do mar (GOULART; LAMBERTS; FIRMINO, 1998), não apresentando desníveis consideráveis no relevo. Está localizada nas faixas subtropicais de alta pressão e sujeita aos ventos vindos do hemisfério norte, formando os ventos alísios de nordeste na região. A velocidade dos ventos varia de $2 \mathrm{~m} / \mathrm{s}$ a $4 \mathrm{~m} / \mathrm{s}$, o que, segundo a classificação da escala de Beaufort, seria caracterizado como "brisas ligeiras" (NASCIMENTO, 1995).

A partir de análise de dados utilizando o programa Analysis SOL-AR (UNIVERSIDADE..., 2013), foi possível obter a rosa dos ventos com a frequência de ocorrência e de predominância de velocidade dos ventos para cada estação do ano de Belém, onde a frequência de ocorrência de vento é predominante a leste, com oscilações de sudeste a nordeste. Os maiores percentuais de incidências são na primavera, com $20 \%$, e no inverno, com pouco mais de $20 \%$, sendo a maior movimentação de ar pelo período da tarde. Conforme análise, pode-se extrair como velocidade média do vento anual o valor de $3 \mathrm{~m} / \mathrm{s}$ em todas as direções. Assim, adotou-se como referências para as simulações a incidência do vento predominando de leste $\left(\alpha=0^{\circ}\right)$ e de nordeste/sudeste $\left(\alpha=45^{\circ}\right)$, e velocidade média de $3 \mathrm{~m} / \mathrm{s}$.

\section{Simulação computacional de ventilação natural urbana com CFD}

$\mathrm{Na}$ modelagem computacional de ventilação natural com interesse no escoamento do entorno das edificações, é necessária a execução de algumas etapas para a construção do modelo simulado, como: construção da geometria, domínio computacional, geração da malha, equações governantes e de turbulência.

\section{Geometrias (cenários de ocupação)}

As geometrias, que representam as quadras, foram modeladas no software Solidworks 10.0, nas dimensões gerais de $168,85 \mathrm{~m}$ x 164,70 m, distanciadas $20 \mathrm{~m}$ (largura das vias urbanas). Considerou-se na construção das geometrias edificações de um e/ou dois pavimentos, blocos com altura de $7 \mathrm{~m}$. Por outro lado, detalhes arquitetônicos, sacadas, varandas, pátios, inclinação de coberturas, representação de espécies arbóreas, calçadas, muros e afastamentos menores que $5 \mathrm{~m}$ entre as edificações foram desconsiderados. Essas premissas geométricas foram necessárias para reduzir o tempo computacional das simulações.

O Solidworks 10.0 possui a limitação de não permitir o uso de comprimentos maiores que 500 $\mathrm{m}$. Consequentemente, nas dimensões das quadras foi aplicada a escala de redução 1/5. Após as simplificações adotadas e a redução de escala, foram modelados os cenários de ocupação e as orientações dominantes dos ventos (leste $\left[\alpha=0^{\circ}\right] \mathrm{e}$ nordeste/sudeste $\left[\alpha=45^{\circ}\right]$ ) em Belém, PA. Como forma de analisar o escoamento entre quadras, partiu-se da premissa de que as quadras estavam circundadas por outras quadras iguais a ela. Isso resultou na criação dos cenários com as quadras agrupadas (Figura 3). 
Figura 3 - Cenários de simulação com contorno das edificações e orientação do vento perpendicular à quadra, $0^{\circ}$, e obliquo à quadra, $45^{\circ}$

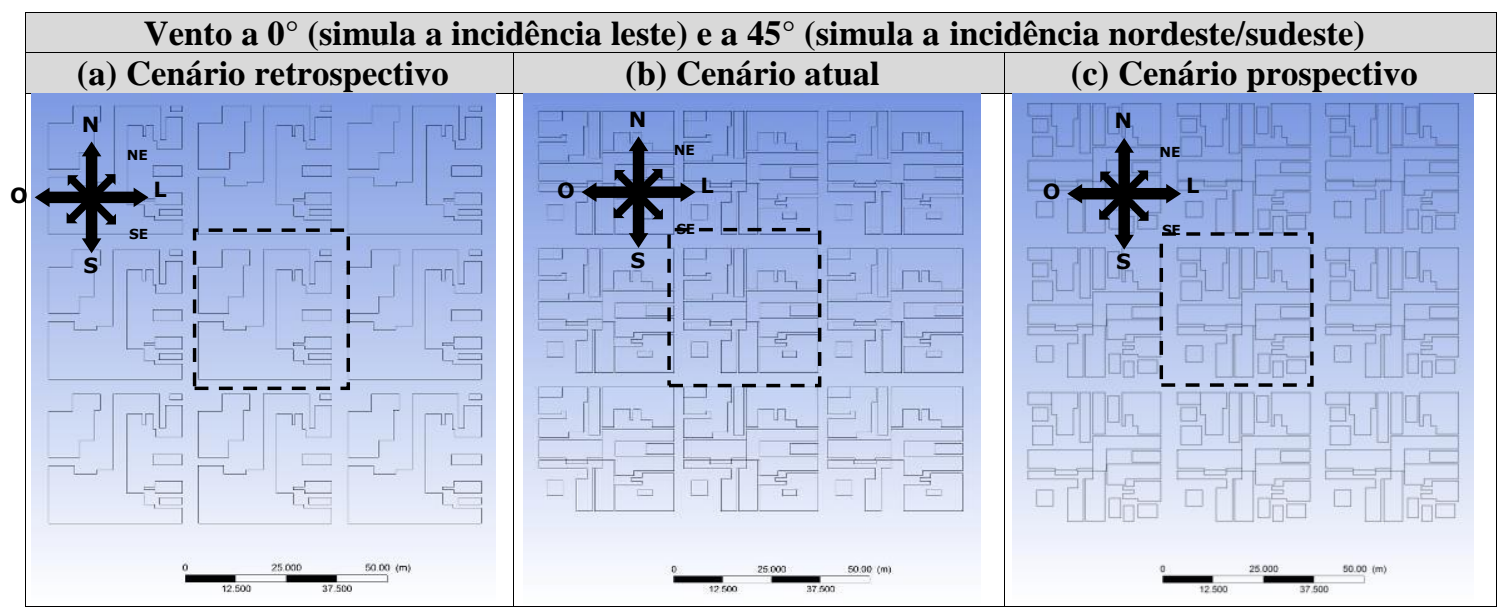

\section{Construção dos domínios}

O domínio computacional simula o escoamento atmosférico. É composto de faces que precisam estar a uma determinada distância do objeto a ser simulado, que são calculadas em função da altura do edifício mais alto a ser simulado e a relação de bloqueio $^{1}$ (FRANKE et al., 2004; FRANKE, 2006; FRANKE et al., 2007). Nas faces do domínio computacional foram inseridas as características do ambiente externo, chamadas de condições de contorno (Quadro 2).

\section{Configurações de malha, equações governantes e critério de convergência}

A malha é a decomposição (discretização) do domínio em volumes menores, chamados de elementos, que foram gerados no Ansys Meshing 15.0 com elementos tetraédricos. Foi aplicado refinamento de malha em locais de interesse como as faces das edificações e nas ruas. Para avaliar a independência de malha, foram realizados três testes de refinamento para cada geometria.

Utilizou-se equações governantes da conservação da massa, da quantidade de movimento (equações de Navier-Stokes) e dos fluxos turbulentos resolvidos por equações do modelo de turbulência k- $\varepsilon$ (RAMPONI; BLOCKEN, 2012). O critério de convergência foi dimensionado para 10-4 (FRANKE, 2006; FRANKE et al., 2007).

\footnotetext{
${ }^{1}$ Relação de bloqueio ou distância de bloqueio é a razão entre a área projetada dos edifícios na direção do fluxo pela secção transversal livre do domínio computacional (FRANKE et al., 2007).
}

\section{Análise dos resultados}

\section{Visualização do escoamento de vento através de planos horizontais}

Foram criados planos horizontais distanciados do solo para visualização dos contornos de velocidade de escoamento do ar, que é a representação de campos de velocidade do vento através de cores. Para isso, estabeleceram-se nove planos em diferentes alturas: $1 \mathrm{~m}$ e $2 \mathrm{~m}$ (nível de pedestre), 3 $\mathrm{m}$ (altura de uma edificação de um pavimento), 10 $\mathrm{m}$ (altura de uma estação meteorológica) e os outros planos de $25 \mathrm{~m}, 55 \mathrm{~m}, 65 \mathrm{~m}, 70 \mathrm{~m}, 85 \mathrm{~m}$ correspondem a alturas aproximadas de edifícios existentes nas quadras. Isso possibilitou a visualização dos efeitos de recuos, uso do solo e verticalização sob a vigência de diferentes planos diretores no escoamento de vento no setor central.

\section{Comparação do potencial de ventilação urbana em diferentes alturas}

Com a finalidade de comparar as possíveis mudanças nos escoamentos das velocidades dos ventos, em razão da legislação vigente para cada Plano Diretor, fez-se a marcação de doze pontos nas quadras miolo (quadra localizada no centro do agrupamento de quadras) de cada cenário para a visualização e comparação das mudanças ocorridas na velocidade do vento. Foram marcados três pontos na face orientada a barlavento e a sotavento, o que possibilitou a comparação da velocidade do vento na entrada e na saída, numa distância de $2 \mathrm{~m}$ da quadra miolo. Com o intuito de visualizar o perfil de velocidade do vento em função das alturas das edificações, os pontos foram estabelecidos a $2 \mathrm{~m}$ (nível de pedestre) e a $5 \mathrm{~m}, 10$ m, $20 \mathrm{~m}, 30 \mathrm{~m}, 40 \mathrm{~m}, 50 \mathrm{~m}, 60 \mathrm{~m}, 70 \mathrm{~m}, 80 \mathrm{~m}, 90$ $\mathrm{m}, 100 \mathrm{~m}$ (alturas aproximadas de edifícios existentes na quadra e em suas proximidades). 
Quadro 2 - Condições de contorno aplicadas ao modelo simulado

\begin{tabular}{|c|c|c|}
\hline Fronteira & Referências & O que é recomendado? \\
\hline Entrada & $\begin{array}{l}\text { Wieringa (1992); Richards e } \\
\text { Roxey (1993); Franke } \text { et al. } \\
\text { (2007); Zhang (2009); Blocken, } \\
\text { Janssen e van Hooff (2012); e } \\
\text { Ramponi e Blocken (2012). }\end{array}$ & $\begin{array}{l}\text { a) Condição de entrada (inlet) com inserção do perfil } \\
\text { de entrada da velocidade média vertical do vento [U] } \\
\text { e equação de cálculo da velocidade de atrito [u*]. } \\
U=\frac{u^{*}}{k} \ln \left(\frac{z+z_{0}}{z_{0}}\right) ; u^{*}=\frac{k \cdot U_{h}}{\ln \left(\frac{h+z_{0}}{z_{0}}\right)} \\
\text { b) Intensidade de turbulência de } 5 \% \text {. } \\
\text { c) Comprimento de rugosidade aerodinâmica de } 2 \mathrm{~m} \\
\text { (edifícios altos). } \\
\text { d) Velocidade média do vento de } 3 \mathrm{~m} / \mathrm{s} \text {. }\end{array}$ \\
\hline Lateral & $\begin{array}{l}\text { Cóstola e Alucci (2011); Franke } \\
\text { (2006); e Blocken, Carmeliet e } \\
\text { Stathopoulos (2007). }\end{array}$ & $\begin{array}{l}\text { Condição de parede (wall), sem rugosidade (free slip } \\
\text { wall). }\end{array}$ \\
\hline Topo & $\begin{array}{l}\text { Blocken, Stathopoulos e } \\
\text { Carmeliet (2007); Brandão } \\
\text { (2009); Blocken e Persoon } \\
\text { (2009); e Cóstola e Alucci (2011). }\end{array}$ & $\begin{array}{l}\text { Condição de parede (wall), sem rugosidade (free slip } \\
\text { wall). }\end{array}$ \\
\hline Saída & $\begin{array}{l}\text { Franke et al. (2004); Ramponi e } \\
\text { Blocken (2012); e An, Fung e } \\
\text { Yim (2013). }\end{array}$ & $\begin{array}{l}\text { Condição de contorno aberta (opening) e pressão } \\
\text { estática igual à zero. }\end{array}$ \\
\hline Piso & $\begin{array}{l}\text { Brandão (2009); e Cóstola e } \\
\text { Alucci (2011). }\end{array}$ & $\begin{array}{l}\text { Condição de parede (wall), no slip wall, com } \\
\text { rugosidade (smooth wall). }\end{array}$ \\
\hline $\begin{array}{l}\text { Parede } \\
\text { (Bloco) }\end{array}$ & $\begin{array}{l}\text { Brandão (2009); e Cóstola e } \\
\text { Alucci (2011). }\end{array}$ & $\begin{array}{l}\text { Condição de parede (wall), no slip wall, com } \\
\text { rugosidade (smooth wall). }\end{array}$ \\
\hline
\end{tabular}

\section{Resultados e discussão}

\section{Análise do comportamento do vento a partir dos efeitos das prescrições urbanísticas nos cenários através de planos horizontais e valores de velocidade do vento}

\section{Cenário retrospectivo com vento orientado a leste $\left[0^{\circ}\right]$}

Tem-se uma situação de adensamento horizontal e baixas alturas, em que a velocidade do vento é reduzida à medida que ultrapassa a primeira quadra e atinge valores menores que $1 \mathrm{~m} / \mathrm{s}$ (Quadro 3a e 3c). Isso acontece em decorrência do adensamento da malha urbana e da baixa permeabilidade, que provoca redução das velocidades e elevação do gradiente de velocidade em virtude do atrito com o tecido urbano. Além disso, desenvolvem-se esteiras de vento nas regiões posteriores às quadras, com zonas de estagnação de ar que se repetem quadra após quadra. Essa situação compromete as trocas de calor e renovação de ar nas edificações e entre elas. Por outro lado, em áreas com exposição direta ao vento predominante e sem obstáculos como as ruas, há um aumento nos valores de velocidade de escoamento de correntes de ar.

Pela análise do perfil de velocidade de vento (Figura 4), ocorrem interferências na velocidade de escoamento do ar até $10 \mathrm{~m}$ de altura. Os baixos valores de velocidade registrados se devem ao adensamento horizontal, gerado pela proximidade das construções. As velocidades são baixas até aproximadamente o plano de $10 \mathrm{~m}$, valor próximo à altura das construções existentes, e acima desse nível a velocidade do vento tende a ser constante e intensa pela não interferência das construções. 
Quadro 3 - Escoamento de vento no cenário retrospectivo com vento orientado a leste $\left[0^{\circ}\right.$ ] nos planos horizontais $1 \mathrm{~m}, 2 \mathrm{~m}, 3 \mathrm{~m}, 10 \mathrm{~m}$

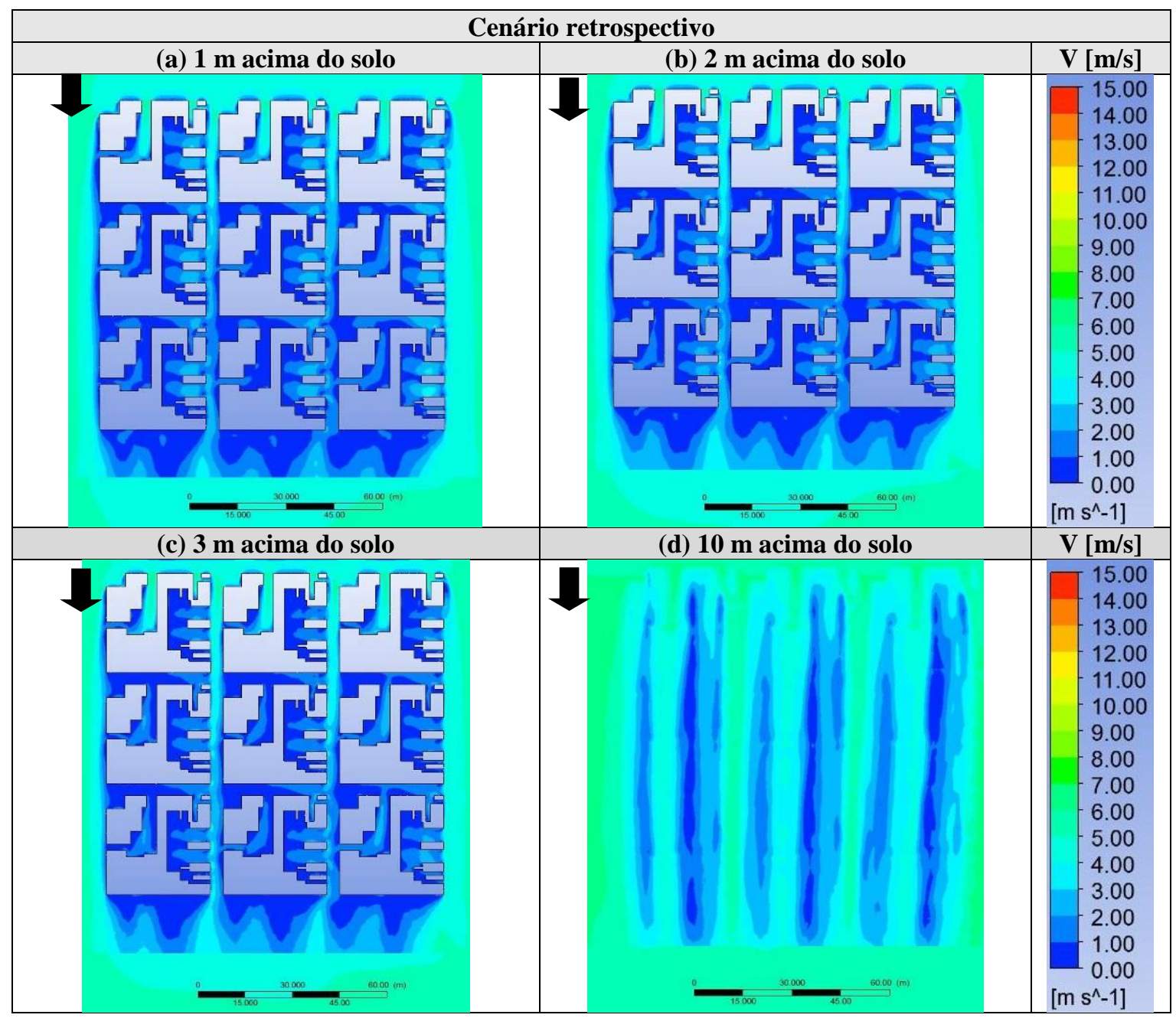

Figura 4 - Perfil de velocidade do vento em função da altura obtido a barlavento e sotavento na quadra miolo para cenário retrospectivo com vento orientado a leste $\left[0^{\circ}\right]$

\section{Perfil de velocidade do vento}

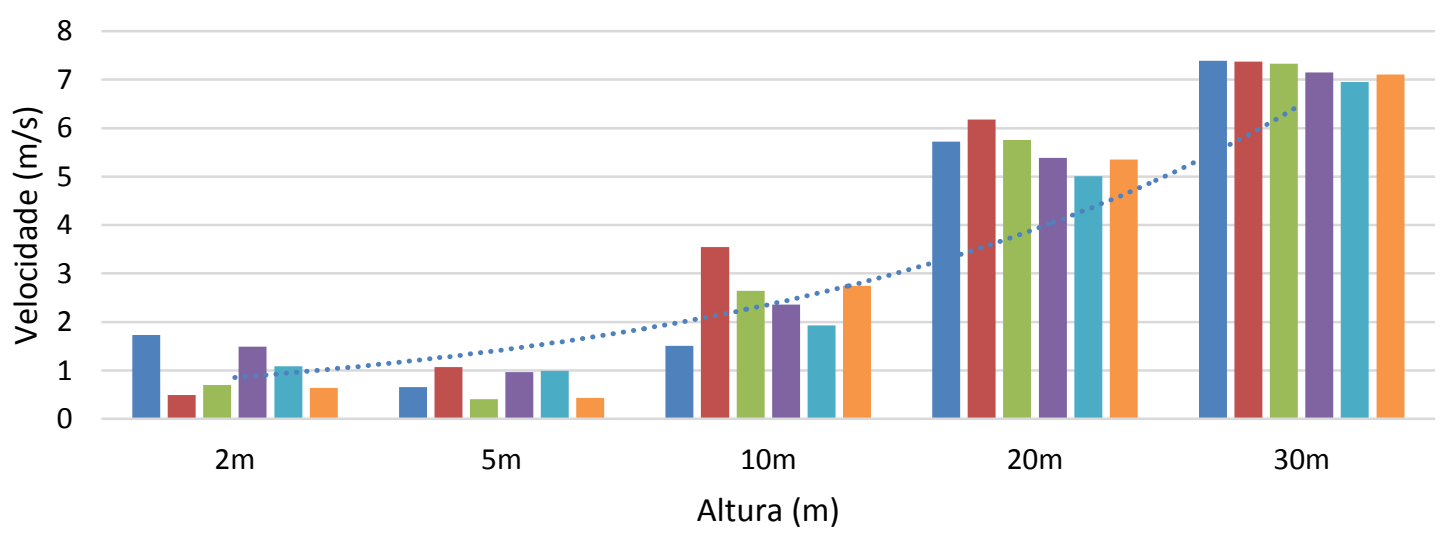

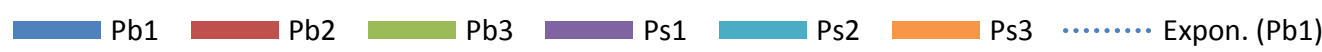




\section{Cenário atual com vento orientado a leste [0 ${ }^{\circ}$ ]}

No cenário atual ocorre uma situação de maior variação de gabaritos e afastamentos entre as edificações. Pela análise dos planos horizontais de 1 m, 2 m e 3 m (Quadro 4a e 4c), pode-se afirmar que há uma aceleração da velocidade do vento entre as ruas até a primeira quadra. Essa situação provoca o efeito de canalização, devido à proximidade entre as construções. Até a primeira quadra, o vento circula entre os afastamentos e vazios das construções, entretanto nas quadras posteriores ocorrem áreas com baixas velocidades de vento e estagnação de ar. Essas interferências são observadas através de sombras de vento e turbulências a sotavento (Quadro $4 \mathrm{j}$ e $4 \mathrm{~m}$ ).

Até o plano de $10 \mathrm{~m}$, ainda é possível visualizar esteiras de vento decorrentes das construções localizadas abaixo desse plano. A partir de $65 \mathrm{~m}$ de altura, começa a ocorrer a diminuição das interferências das barreiras físicas.

Pela análise das informações da Figura 5, pôde-se concluir que a partir dos $70 \mathrm{~m}$ de altura a velocidade do vento passa a aumentar de forma constante, e que os valores de velocidade abaixo desse plano possuem velocidades mais baixas, principalmente quando estão à frente ou atrás de construções altas.

Quadro 4 - Escoamento de vento no cenário atual com vento orientado a leste $\left[0^{\circ}\right]$ nos planos horizontais 1 $\mathrm{m}, 2 \mathrm{~m}, 3 \mathrm{~m}, 10 \mathrm{~m}, 25 \mathrm{~m}, 55 \mathrm{~m}, 65 \mathrm{~m}, 70 \mathrm{~m}$ e $85 \mathrm{~m}$ - Planos verticais na quadra miolo com velocidade do vento e indicação de corte (Continua...)

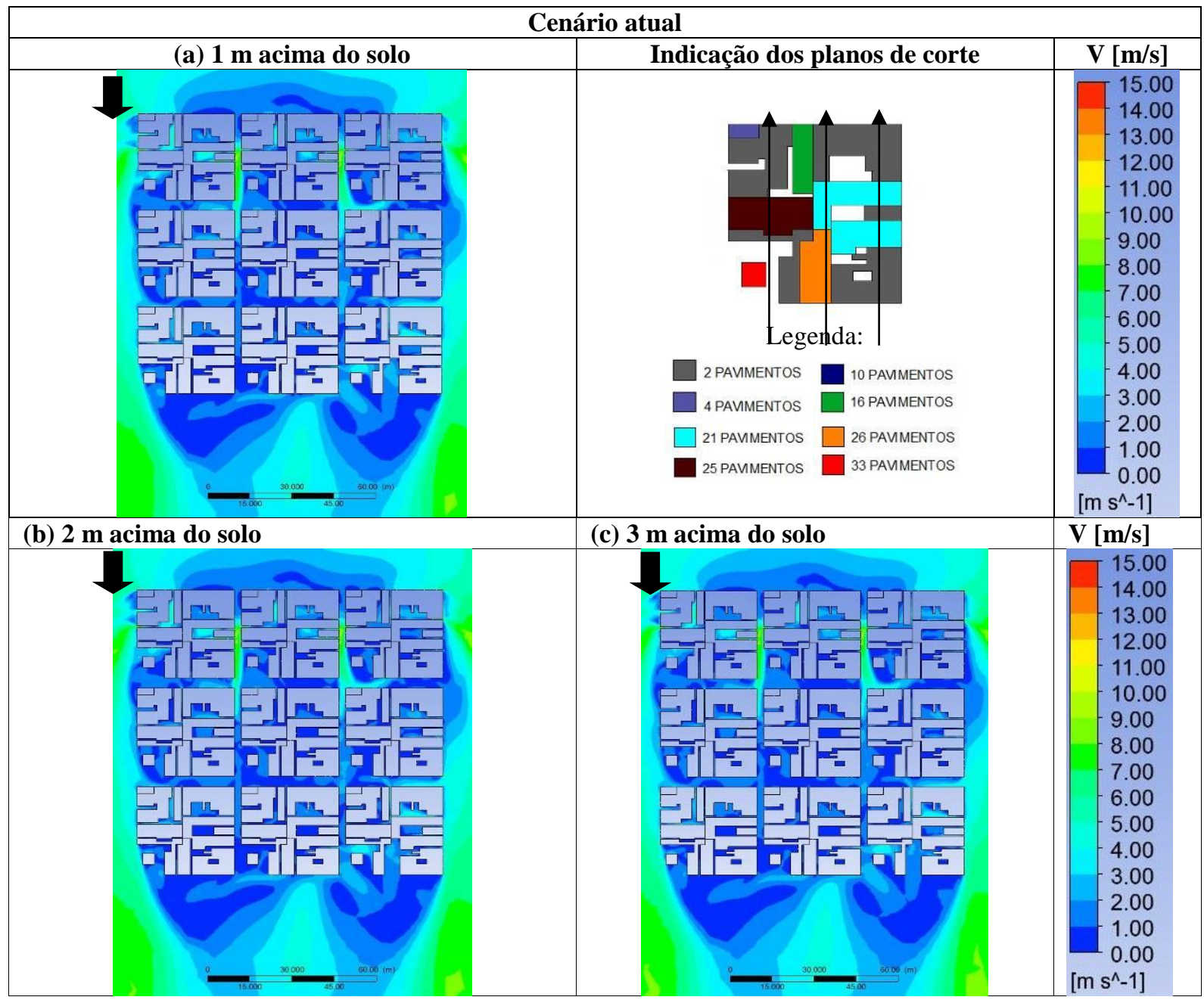


Quadro 4 - Escoamento de vento no cenário atual com vento orientado a leste $\left[0^{\circ}\right.$ ] nos planos horizontais 1 $\mathrm{m}, 2 \mathrm{~m}, 3 \mathrm{~m}, 10 \mathrm{~m}, 25 \mathrm{~m}, 55 \mathrm{~m}, 65 \mathrm{~m}, 70 \mathrm{~m}$ e $85 \mathrm{~m}$ - Planos verticais na quadra miolo com velocidade do vento e indicação de corte (continuação)

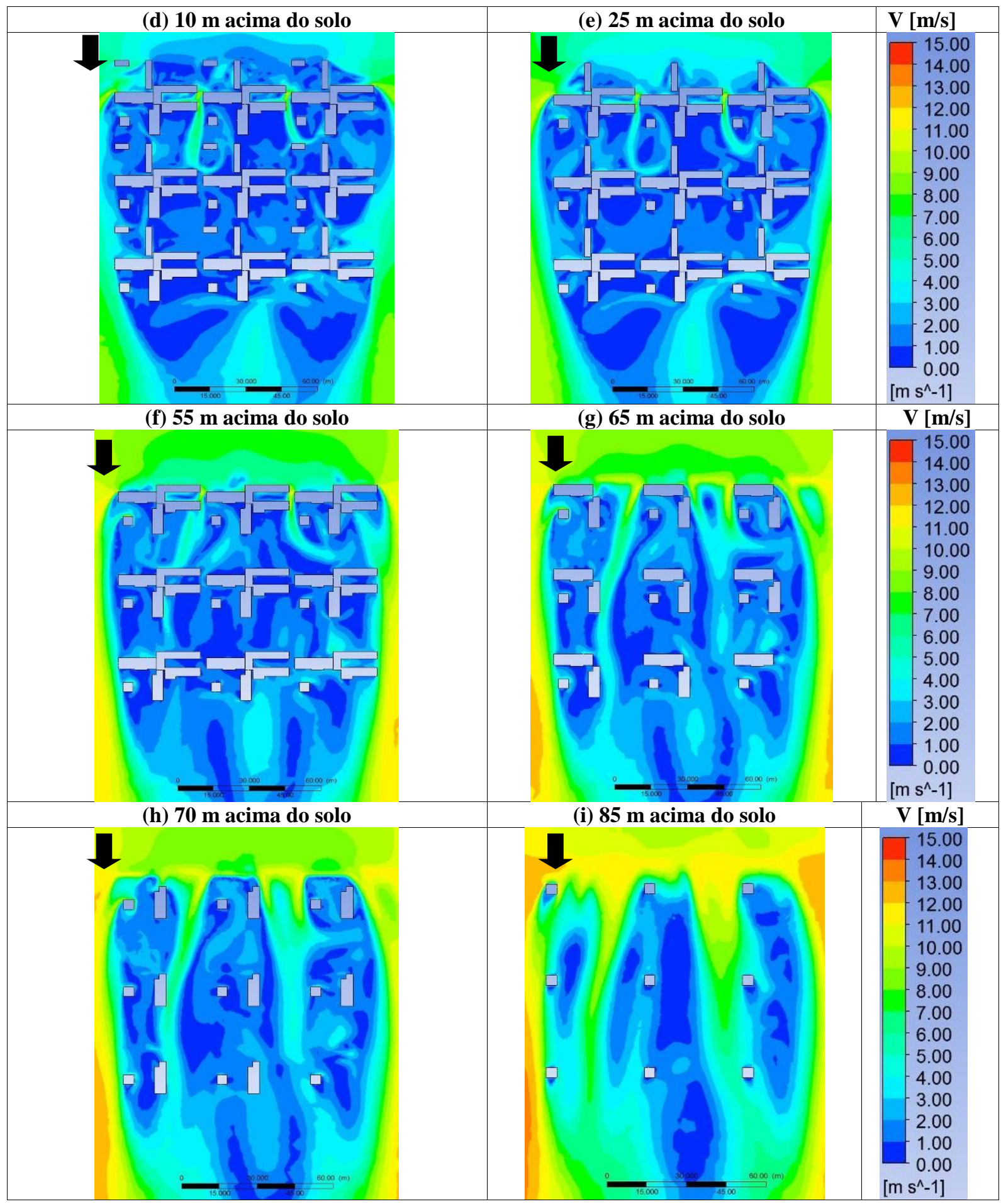


Quadro 4 - Escoamento de vento no cenário atual com vento orientado a leste $\left[0^{\circ}\right.$ ] nos planos horizontais 1 $\mathrm{m}, 2 \mathrm{~m}, 3 \mathrm{~m}, 10 \mathrm{~m}, 25 \mathrm{~m}, 55 \mathrm{~m}, 65 \mathrm{~m}, 70 \mathrm{~m}$ e $85 \mathrm{~m}$ - Planos verticais na quadra miolo com velocidade do vento e indicação de corte (continuação)

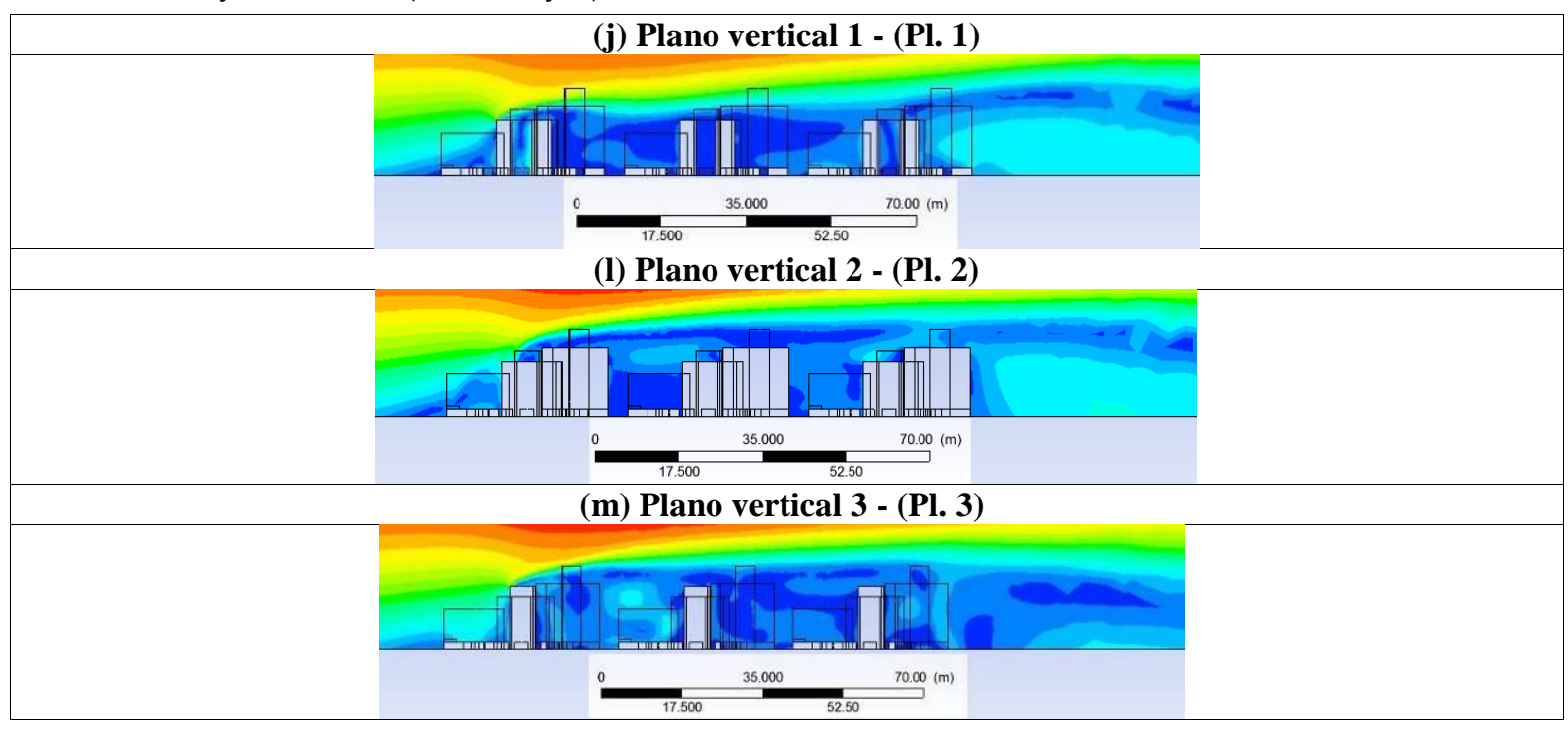

Figura 5 - Perfil de velocidade do vento em função da altura obtido a barlavento e sotavento na quadra miolo para cenário atual com vento orientado a leste $\left[0^{\circ}\right]$

\section{Perfil de velocidade do vento}

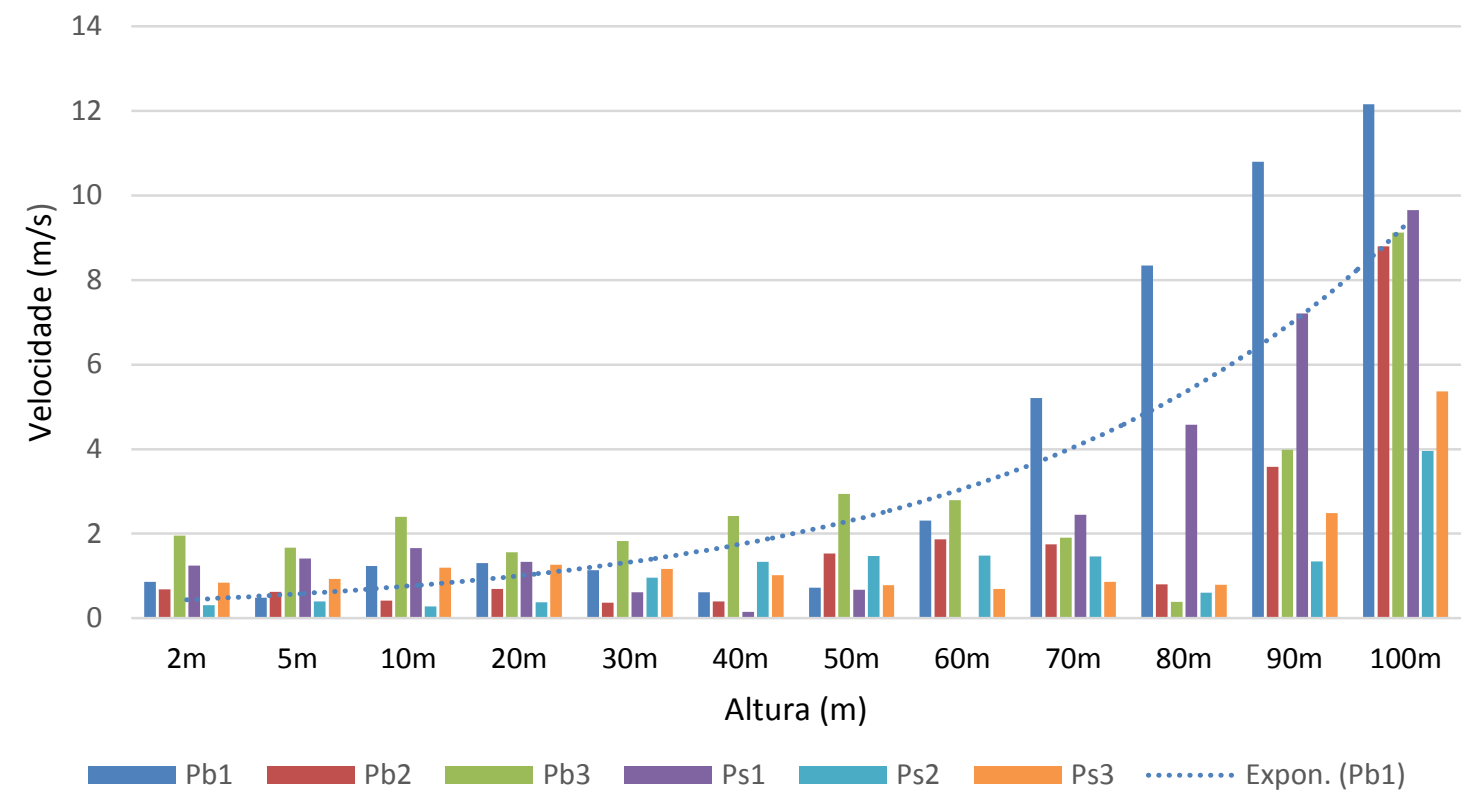

\section{Cenário prospectivo com vento orientado a leste $\left[0^{\circ}\right]$}

Este cenário apresenta um panorama de maior verticalização. Nas primeiras quadras ocorre 0 efeito de canalização do vento entre as ruas no sentido do vento predominante, contudo há pouca circulação de ar entre as edificações (Quadro 5a e 5c). A partir dos $10 \mathrm{~m}$ de altura é possível perceber as interferências provocadas pelas esteiras de vento entre quadras, ruas e edifícios próximos (Quadro 5j e $5 \mathrm{~m})$. Até $70 \mathrm{~m}$ de altura se visualiza a estagnação de vento em grandes áreas, gerada principalmente pelas sombras de vento advindas dos edifícios altos. Essa situação se intensifica ainda mais em função da forma das edificações, que em alguns casos possui dimensão alongada perpendicular ao vento predominante. Estas representam barreiras ao fluxo de vento em função da proximidade que estão das outras construções. Contudo, essa condição começa a se modificar a partir do plano de $80 \mathrm{~m}$, devido à baixa influência das construções. 
Quadro 5 - Escoamento de vento no cenário prospectivo com vento orientado a leste $\left[0^{\circ}\right.$ ] nos planos horizontais $1 \mathrm{~m}, 2 \mathrm{~m}, 3 \mathrm{~m}, 10 \mathrm{~m}, 25 \mathrm{~m}, 55 \mathrm{~m}, 65 \mathrm{~m}, 70 \mathrm{~m}$ e $85 \mathrm{~m}$ - Planos verticais na quadra miolo com velocidade do vento e indicação de corte (Continua...)

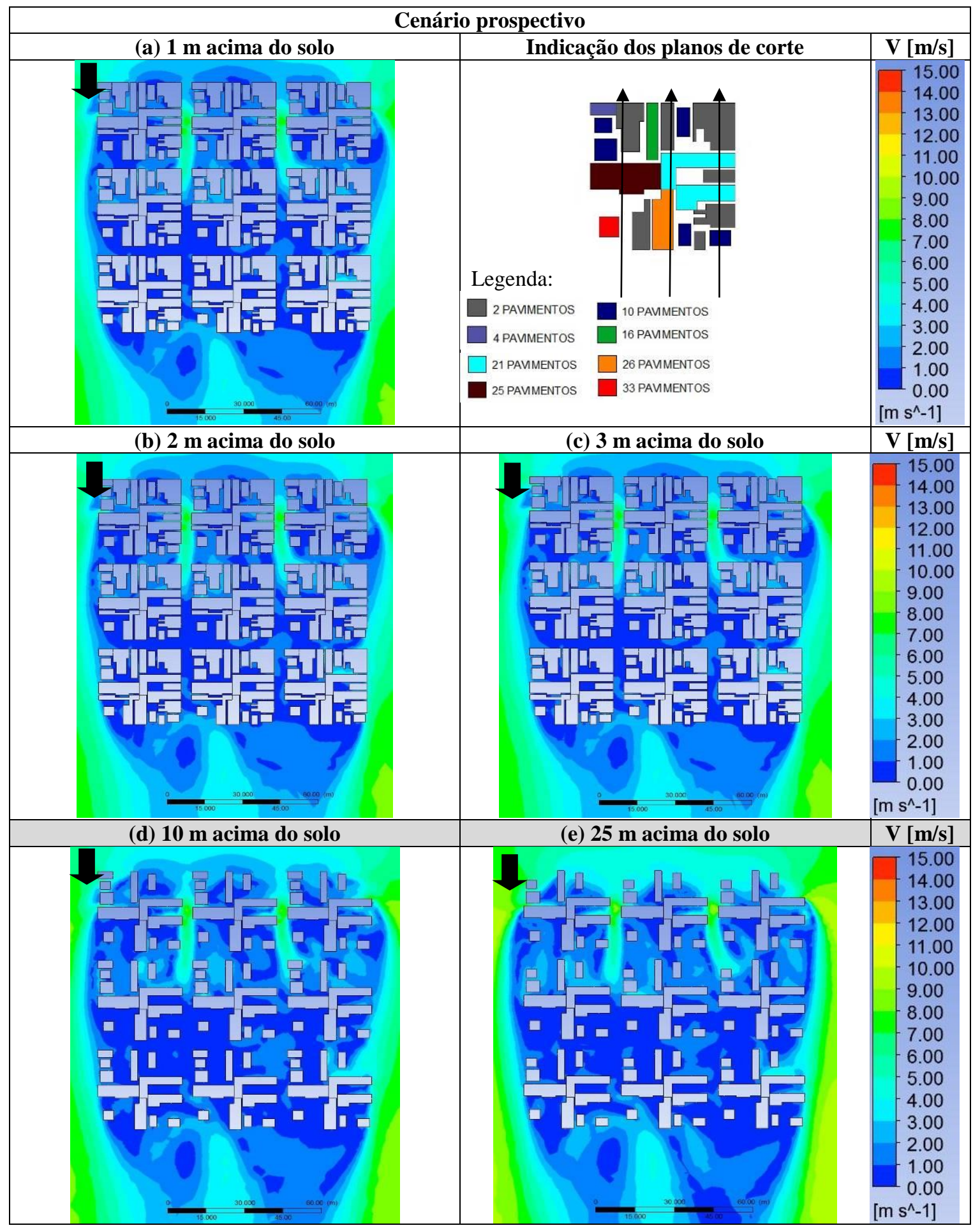


Quadro 5 - Escoamento de vento no cenário prospectivo com vento orientado a leste [0 ${ }^{\circ}$ ] nos planos horizontais $1 \mathrm{~m}, 2 \mathrm{~m}, 3 \mathrm{~m}, 10 \mathrm{~m}, 25 \mathrm{~m}, 55 \mathrm{~m}, 65 \mathrm{~m}, 70 \mathrm{~m}$ e $85 \mathrm{~m}$ - Planos verticais na quadra miolo com velocidade do vento e indicação de corte (continuação)

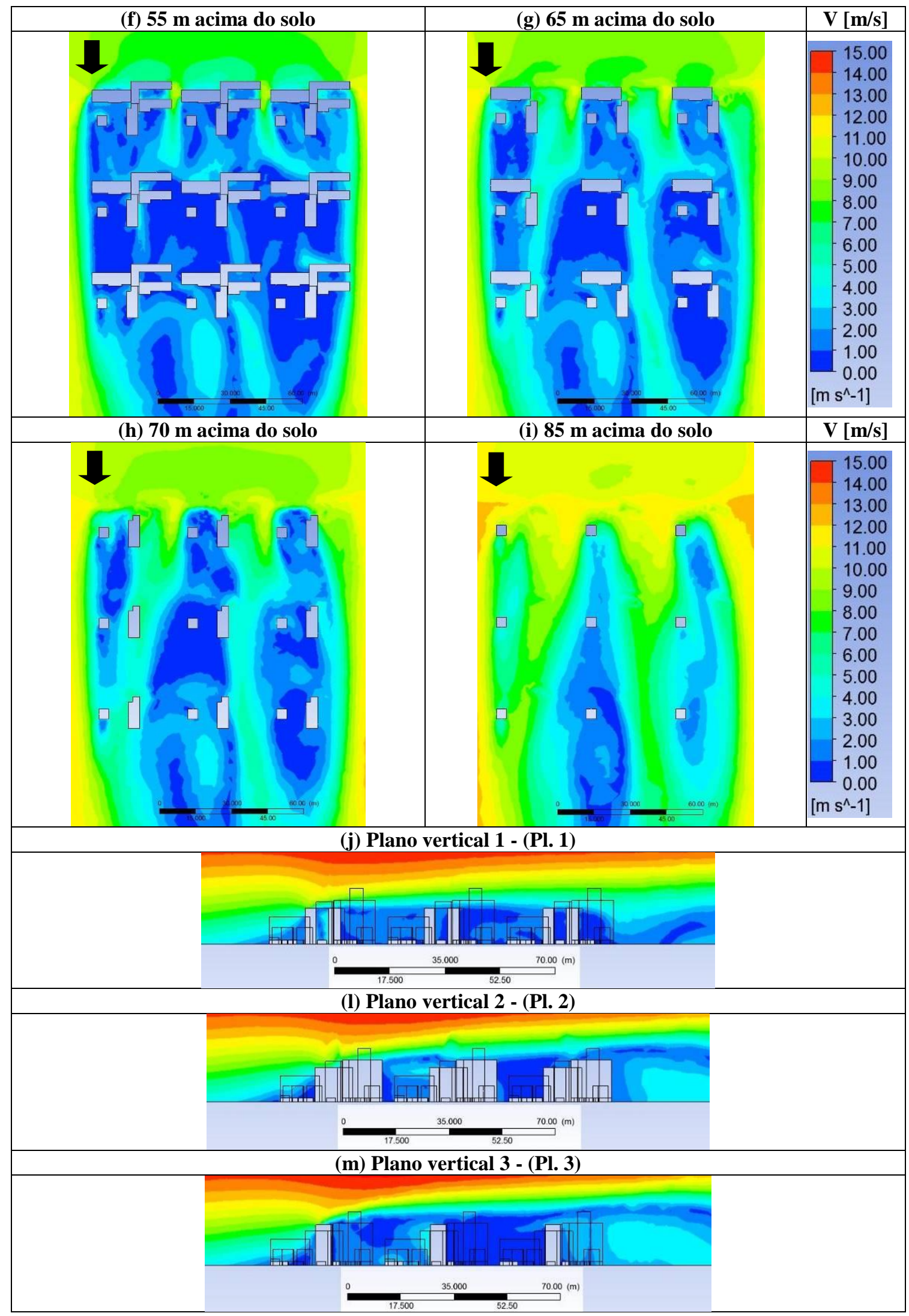


Na Figura 6, até $60 \mathrm{~m}$ de altura têm-se baixas velocidades de ar, contudo a partir de $70 \mathrm{~m}$ observa-se que os valores de velocidade aumentam à medida que se elevam os planos horizontais. Essa condição se verifica pelo fato de os planos mais altos apresentarem baixa interferência da rugosidade do solo.

\section{Cenário retrospectivo com vento orientado a nordeste/sudeste $\left[45^{\circ}\right]$}

Ao observar os planos do cenário retrospectivo com orientação a $45^{\circ}$, é possível afirmar que esses possuem melhores condições de infiltração do vento que o cenário retrospectivo orientado a $0^{\circ}$. O escoamento de ar no cenário retrospectivo a $45^{\circ}$ adentra as ruas e os vazios das construções com velocidade de até $5 \mathrm{~m} / \mathrm{s}$, mesmo com o adensamento horizontal (Quadro 6a e 6c). Percebem-se áreas com estagnação de ar, contudo em número menos expressivo do que o apresentado no cenário retrospectivo a $0^{\circ}$, devido à inclinação das quadras que favorecem a infiltração dos ventos predominantes.

Ao analisar a Figura 7, nota-se que a velocidade do vento é baixa até $5 \mathrm{~m}$ de altura, correspondendo aproximadamente ao gabarito médio dessas construções. Acima dessa altura, a velocidade do vento tende a ser alta e menos turbulenta acima da malha urbana.

\section{Cenário atual com vento orientado a nordeste/sudeste $\left[45^{\circ}\right]$}

O cenário atual com vento orientado a $45^{\circ}$ apresenta melhor infiltração de vento do que quando orientado a $0^{\circ}$. As condições de fluxo de ar são potencializadas pela permeabilidade e redução da interferência da rugosidade na malha urbana (Quadro 7d e 7i). Até $10 \mathrm{~m}$ de altura são observáveis as influências das esteiras de vento advindas das construções que estão abaixo desse plano, mas esse panorama apresenta mudanças a partir de $25 \mathrm{~m}$. Nessa altura, ainda são sentidas as interferências das construções em planos inferiores, todavia a distribuição do fluxo de vento começa a exibir melhoras devido à redução das barreiras físicas (Quadro 7e e 7i). Nos planos verticais (Quadro 7j e 7m), observa-se que as edificações vizinhas provocam interferências no escoamento de vento e que essa situação pode ser minimizada pela inserção de afastamentos generosos entre as construções.

Pela análise da Figura 8, os valores de velocidades a barlavento são baixos principalmente no Peld1 e Peld2, pois estão dispostos logo à frente de edificações. Nos pontos Psld2 e Psld3 a sotavento têm-se baixos valores de velocidade, pois ocorre a recirculação de vento na região posterior a esses pontos. A partir de $70 \mathrm{~m}$ de altura os valores de velocidade começam a ganhar velocidade e a se estabilizarem.

Figura 6 - Perfil de velocidade do vento em função da altura obtido a barlavento e sotavento na quadra miolo para cenário prospectivo com vento orientado a leste $\left[0^{\circ}\right]$

\section{Perfil de velocidade do vento}

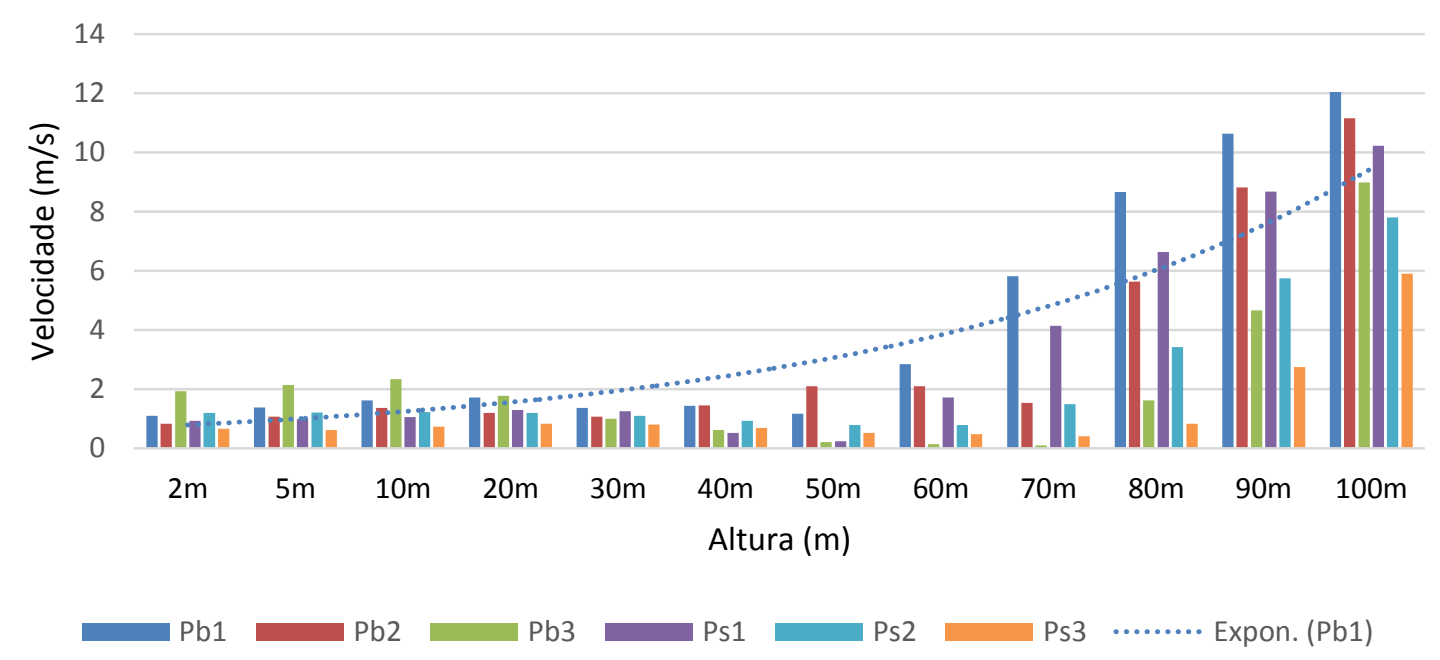


Quadro 6 - Escoamento de vento no cenário retrospectivo com vento orientado a nordeste/sudeste [ $45^{\circ}$ ] nos planos horizontais $1 \mathrm{~m}, 2 \mathrm{~m}, 3 \mathrm{~m}$ e $10 \mathrm{~m}$

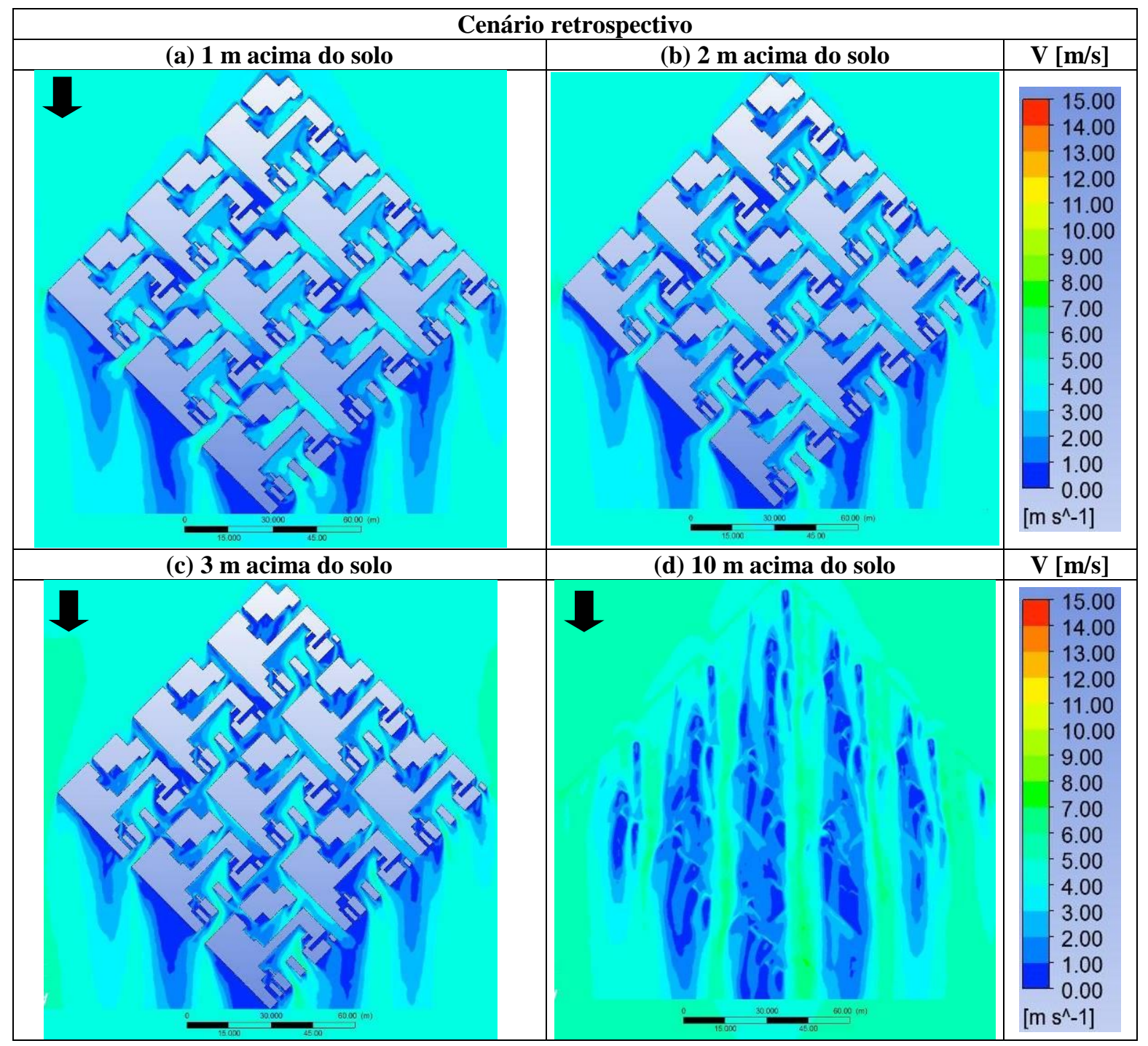

Figura 7 - Perfil de velocidade do vento em função da altura obtido a barlavento e sotavento na quadra miolo para cenário retrospectivo com vento orientado a nordeste/sudeste $\left[45^{\circ}\right.$ ]

\section{Perfil de velocidade do vento}
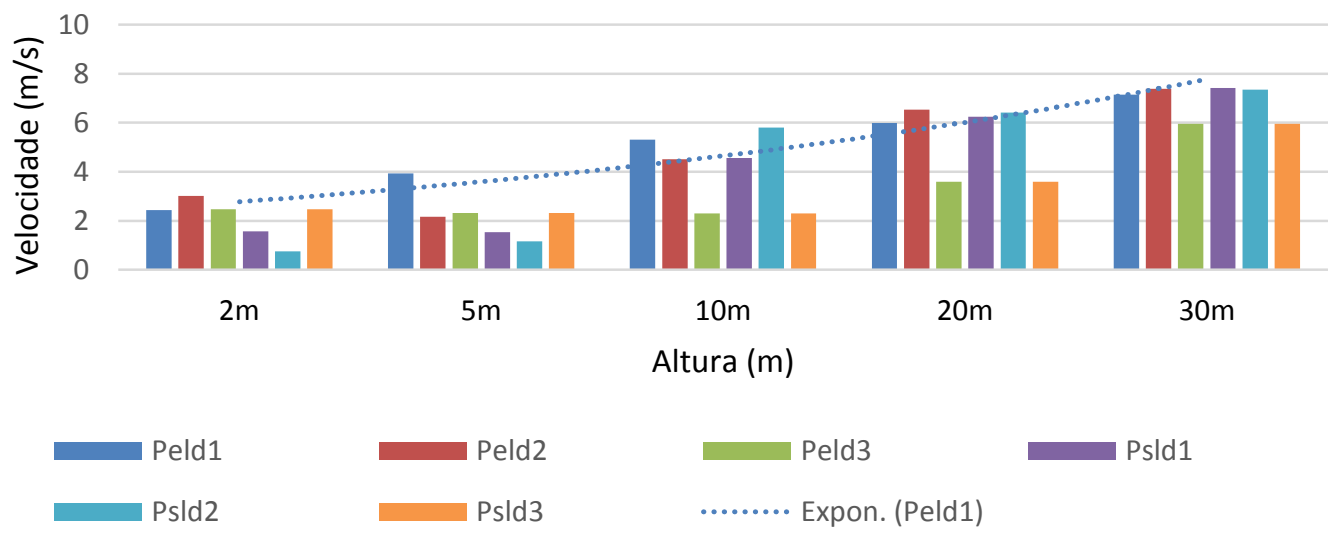
Quadro 7 - Escoamento de vento no cenário atual com vento orientado a nordeste/sudeste [45 ${ }^{\circ}$ ] nos planos horizontais $1 \mathrm{~m}, 2 \mathrm{~m}, 3 \mathrm{~m}, 10 \mathrm{~m}, 25 \mathrm{~m}, 55 \mathrm{~m}, 65 \mathrm{~m}, 70 \mathrm{~m}$ e $85 \mathrm{~m}$ - Planos verticais na quadra miolo com velocidade do vento e indicação de corte (Continua...)

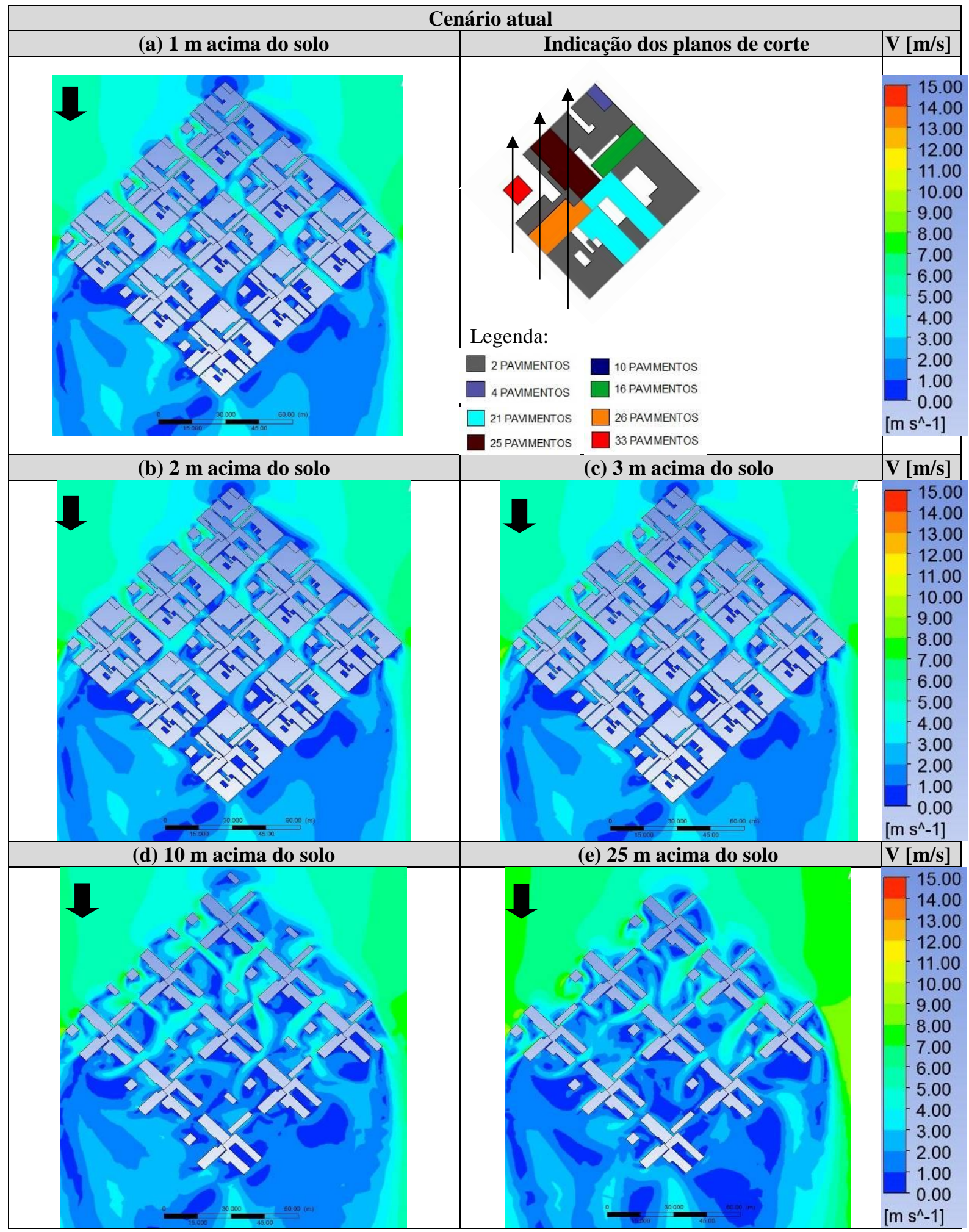


Quadro 7 - Escoamento de vento no cenário atual com vento orientado a nordeste/sudeste [45 ${ }^{\circ}$ ] nos planos horizontais $1 \mathrm{~m}, 2 \mathrm{~m}, 3 \mathrm{~m}, 10 \mathrm{~m}, 25 \mathrm{~m}, 55 \mathrm{~m}, 65 \mathrm{~m}, 70 \mathrm{~m}$ e $85 \mathrm{~m}$ - Planos verticais na quadra miolo com velocidade do vento e indicação de corte (continuação)

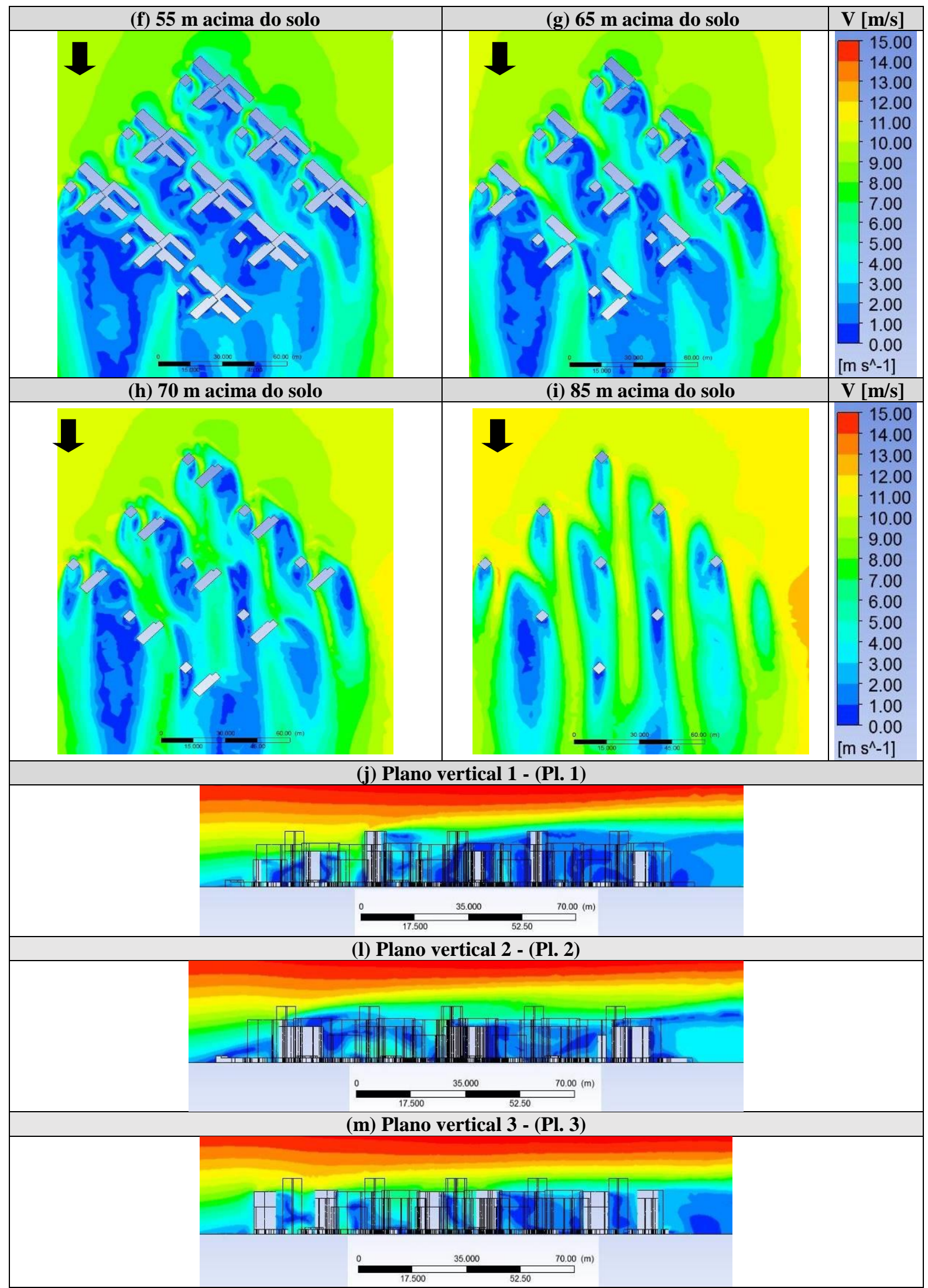


Figura 8 - Perfil de velocidade do vento em função da altura obtido a barlavento e sotavento na quadra miolo para cenário atual com vento orientado a nordeste/sudeste $\left[45^{\circ}\right]$

\section{Perfil de Velocidade do Vento}

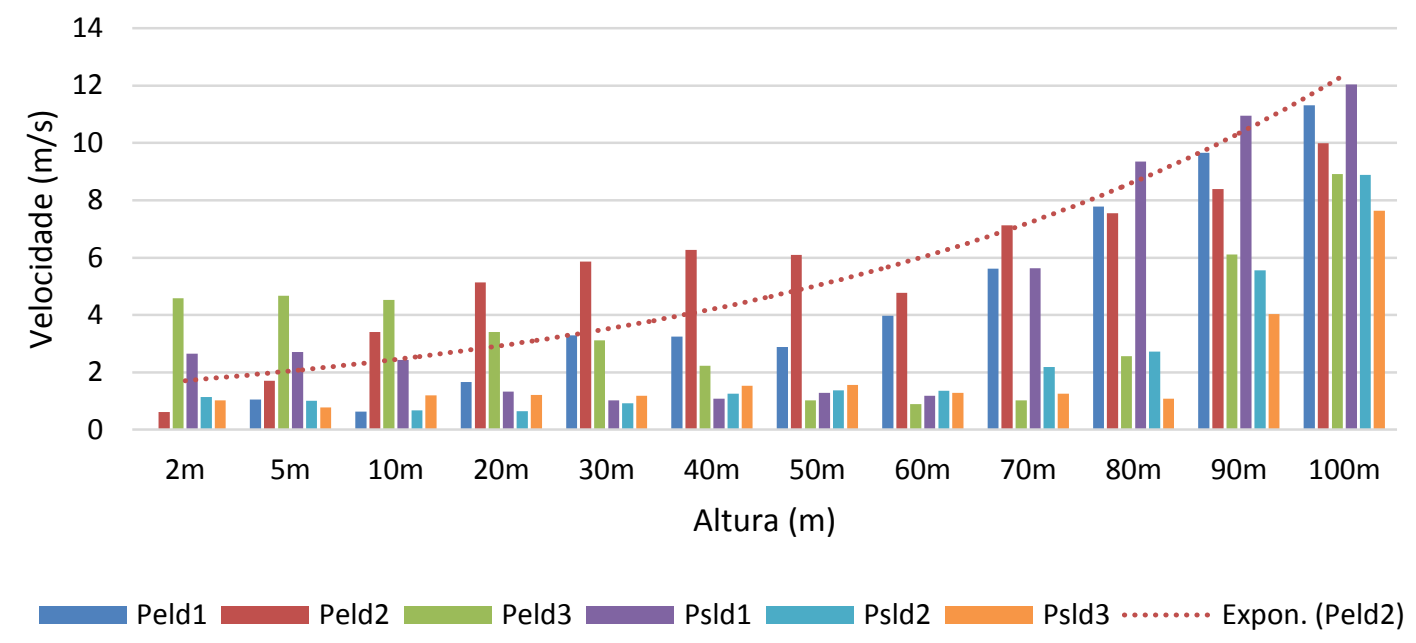

\section{Cenário prospectivo com vento orientado a nordeste/sudeste $\left[45^{\circ}\right]$}

No cenário prospectivo nordeste/sudeste $\left(45^{\circ}\right)$ observam-se melhores condições de circulação de vento quando comparado ao vento orientado a leste $\left(0^{\circ}\right)$. Esse cenário possui menos áreas de estagnação de vento nas entradas das quadras, devido aos afastamentos entre as edificações. Isso produz melhores condições de permeabilidade e porosidade entre as construções (Quadro 8). Assim como nas outras simulações, as edificações vizinhas representam barreiras ao fluxo de vento pela formação de sombras de vento. Essa situação pode gerar turbulências na região posterior às construções, dependendo da distância entre as edificações. Nos planos verticais (Quadro 8j e 8m) observam-se interferências no escoamento do vento até aproximadamente $35 \mathrm{~m}$ de altura, ou seja, próximo ao valor do edifício mais alto localizado na quadra, e o comprimento da esteira de vento se forma em função da altura das construções.

Na Figura 9, os valores de velocidade do vento são altos quando comparados aos cenários retrospectivo e atual a $45^{\circ}$. Isso se deve aos afastamentos entre as construções, que permitem maior permeabilidade do vento. A sotavento, a velocidade tende a reduzir logo após a construção e cresce à medida que se afasta dos planos próximos às edificações. 
Quadro 8 - Escoamento de vento no cenário prospectivo com vento orientado a nordeste/sudeste [ $45^{\circ}$ ] nos planos horizontais $1 \mathrm{~m}, 2 \mathrm{~m}, 3 \mathrm{~m}, 10 \mathrm{~m}, 25 \mathrm{~m}, 55 \mathrm{~m}, 65 \mathrm{~m}, 70 \mathrm{~m}$ e $85 \mathrm{~m}$ - Planos verticais na quadra miolo com velocidade do vento e indicação de corte (Continua...)

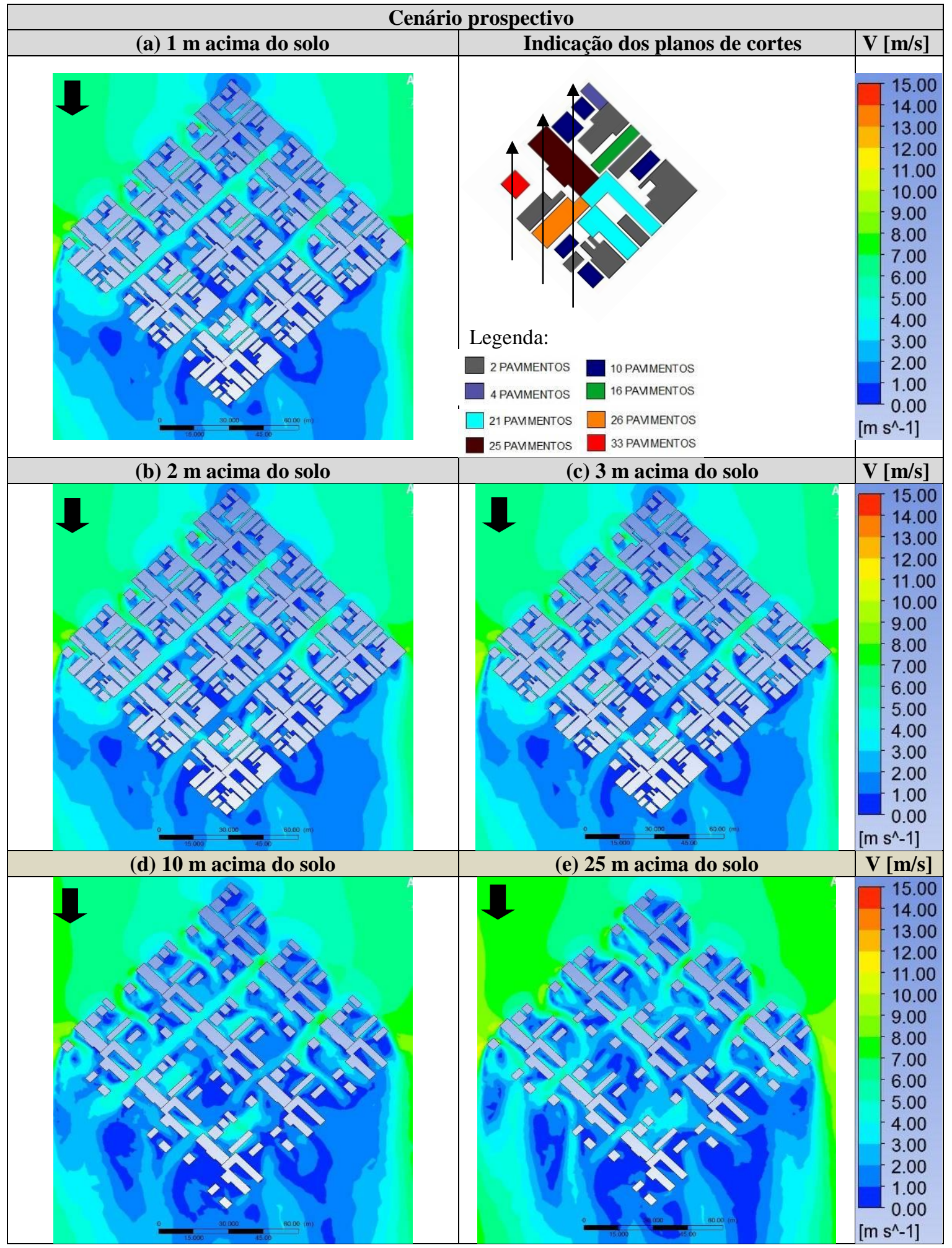


Quadro 8 - Escoamento de vento no cenário prospectivo com vento orientado a nordeste/sudeste [ $45^{\circ}$ ] nos planos horizontais $1 \mathrm{~m}, 2 \mathrm{~m}, 3 \mathrm{~m}, 10 \mathrm{~m}, 25 \mathrm{~m}, 55 \mathrm{~m}, 65 \mathrm{~m}, 70 \mathrm{~m}$ e $85 \mathrm{~m}$ - Planos verticais na quadra miolo com velocidade do vento e indicação de corte (continuação)

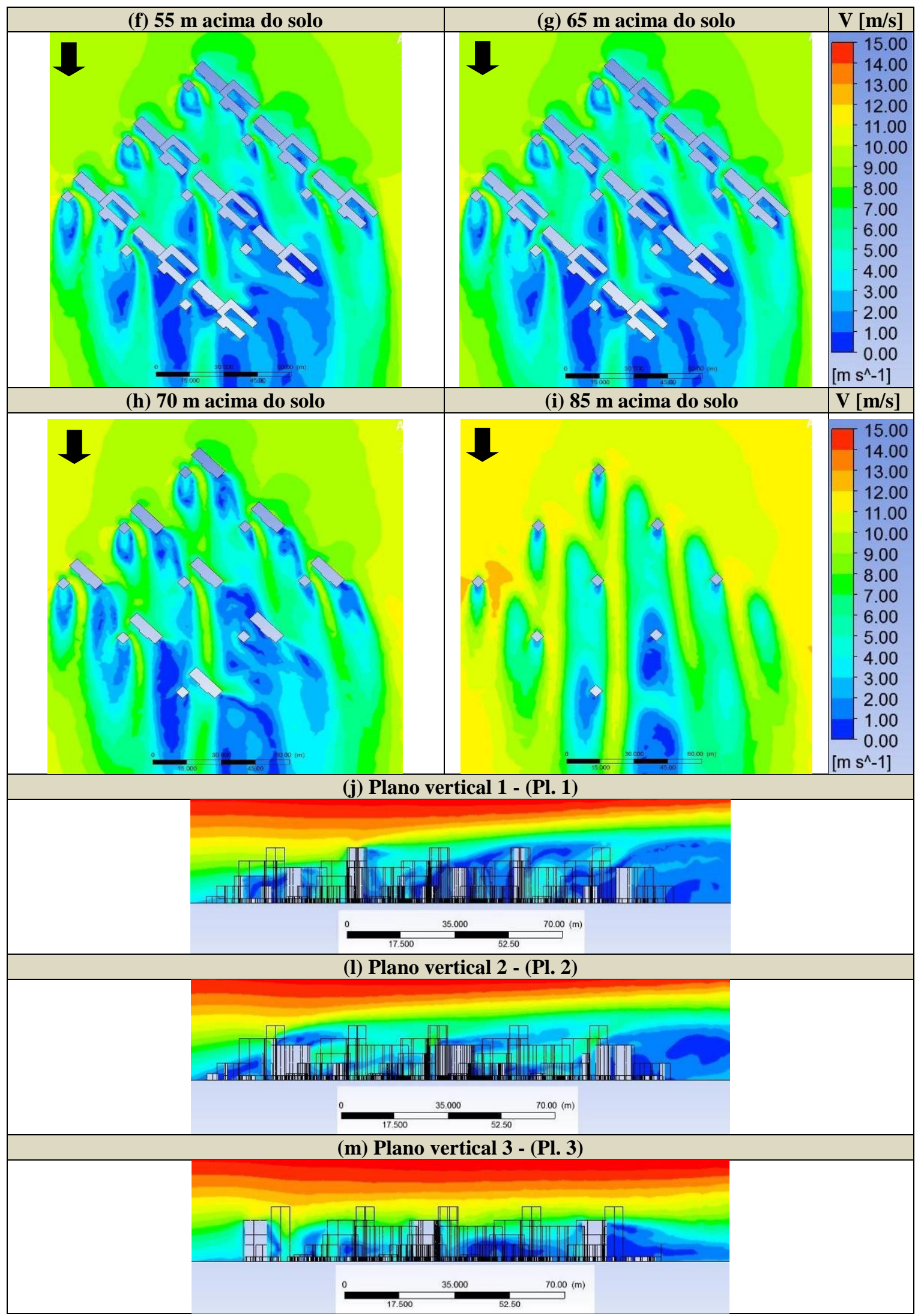


Figura 9 - Perfil de velocidade do vento em função da altura obtido a barlavento e sotavento na quadra miolo para cenário prospectivo com vento orientado a nordeste/sudeste $\left[45^{\circ}\right]$

\section{Perfil de velocidade de vento}

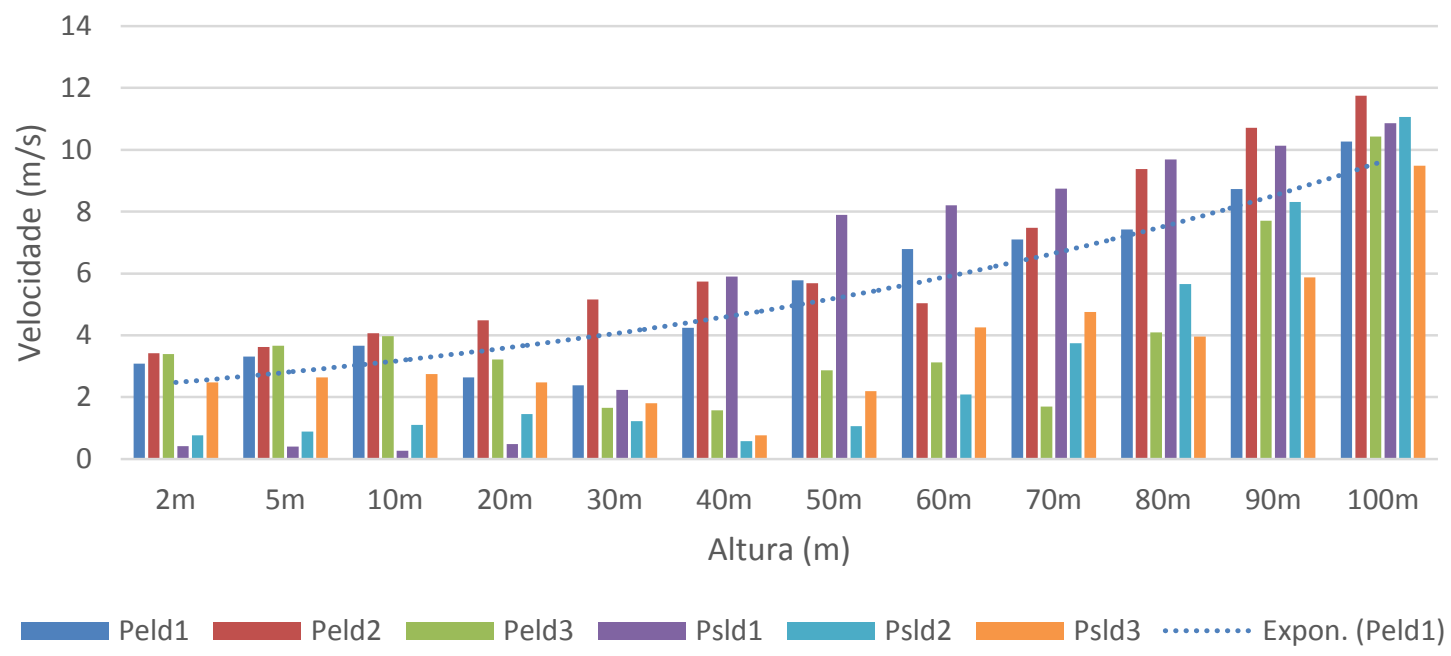

\section{Conclusão}

A partir da análise dos cenários modelados para Belém, PA, conforme os planos diretores urbanos de 1993 e 2008, conclui-se que o adensamento urbano e a redução dos recuos entre as edificações representam as maiores preocupações ao impedimento do escoamento do vento nas quadras simuladas. Essas configurações urbanísticas favorecem a redução da velocidade do vento e do seu potencial de ventilação do espaço urbano.

É importante ressaltar que a verticalização sem recuos adequados dos cenários simulados pode interferir na redução da velocidade de ar nos espaços urbanos. Fazendo uma analogia aos cenários adensados horizontalmente, os cenários verticalizados sem afastamentos seriam como cenários adensados, visto que não possuem afastamentos significativos entre si e fazem uso intenso do solo urbano, através de edificações em uma determinada área. Esse conjunto de características apresentado anteriormente pressupõe uma redução da potencialidade de ventilação e escoamento de ar entre as construções. Por outro lado, os impactos negativos gerados pelos altos gabaritos podem ser contornados ou minimizados, por meio da aplicação de afastamentos proporcionais às alturas das construções.

Nos cenários retrospectivos ocorreu o adensamento horizontal e os afastamentos reduzidos entre as construções. Essa condição favorece a redução à ventilação e baixas velocidades de ar entre construções e ruas dos cenários simulados. Os cenários atuais, referentes à legislação urbanística de 2008, expuseram melhores condições de infiltração e permeabilidade do ar entre as construções do que os cenários retrospectivos, devido aos maiores recuos dos edifícios de maior gabarito.

Por outro lado, o cenário prospectivo, que satisfaz um panorama para daqui a 15 anos, apresentou condições ainda melhores de circulação de ar entre as edificações do que os cenários retrospectivo e atual. Isso aconteceu em função dos afastamentos entre os novos edifícios construídos e a diminuição do adensamento horizontal.

No cenário prospectivo foi inserida maior quantidade de construções verticalizadas, mas as interferências dessas edificações foram minimizadas pelos afastamentos entre as construções. As legislações urbanísticas utilizadas nessa pesquisa, de modo geral, orientam que seja aplicado aumento de recuos quando se eleva o gabarito das construções conforme quadro de modelos urbanísticos. Entretanto, seria necessário um estudo aprofundado para avaliar até quanto as implicações e dimensões desses recuos nas construções podem contribuir para o escoamento de ar e a melhoria de potencial de ventilação na área estudada.

Outro aspecto importante é a forma e orientação do edifício em relação à direção do vento, visto que esses aspectos podem potencializar as condições de circulação do ar entre as construções e nas ruas. Isso pôde ser observado no comportamento do escoamento de vento obtido nas simulações 
orientadas a nordeste/sudeste $\left(45^{\circ}\right)$. Essas se mostraram superiores quanto à velocidade do vento e ao potencial de ventilação cruzada, quando comparadas aos cenários orientados a leste $\left(0^{\circ}\right)$.

\section{Referências}

AL-SALLAL, K. A.; AL-RAIS, L. Outdoor Airflow Analysis and Potential for Passive Cooling in the Modern Urban Context of Dubai. Renewable Energy, v. 38, n. 1, p. 40-49, 2012.

AN, K.; FUNG, J. C. H.; YIM, S. H. L. Sensitivity of Inflow Boundary Conditions on Downstream Wind and Turbulence Profiles Through Buildings Obstacles Using a CFD Approach. Journal of Wind Engineering and Industrial Aerodynamics, v. 115, 137-149, 2013.

ASFOUR, O. S. Prediction of Wind Environment in Different Grouping Patterns of Housing Blocks. Energy and Building, v. 42, n. 11, p. 2061-2069, 2010.

BELÉM. Lei no 8.655, de 30 de julho de 2008. Disponível em:

<http://www.belem.pa.gov.br/planodiretor/Plano_ diretor_atual/Lei_N8655-08_plano_diretor.pdf $>$. Acesso em: 11/04/12.

BELÉM. Lei $\mathbf{n}^{\circ} \mathbf{7 6 0 3}$, de 13 de janeiro de 1993 de Belém. Belém: 1993. Disponível em:

<http://www.jusbrasil.com.br/legislacao/585164/le i-7603-93-belem-pa>. Acesso em: 11/04/12.

BLOCKEN, B.; CARMELIET, J.;

STATHOPOULOS, T. CFD Evaluation of the Wind Speed Conditions in Passages Between Buildings-Effect of Wall-Function Roughness Modifications on the Atmospheric Boundary Layer Flow. Journal of Wind Engineering and Industrial Aerodynamics, v. 95, n. 9/11, p. 941962, 2007.

BLOCKEN, B.; JANSSEN, W. D.; VAN HOOFF, T. CFD Simulation for Pedestrian Wind Comfort and Wind Safety in Urban Areas: general decision framework and case study for the Eindhoven University campus. Environment Modelling and Software, 2012.

BLOCKEN, B; PERSOON, J. Pedestrian wind Comfort Around a Large Football Stadium in an Urban Environment: CFD simulation, validation and application of the new Dutch wind nuisance standard. Journal of Wind Engineering and Industrial Aerodynamics, v. 95, n. 9/11, p. 941962, 2009.
BRANDÃO, R. S. As Interações Espaciais Urbanas e o Clima. São Paulo, 2009. Tese (Doutorado em Engenharia Civil) - Escola de Engenharia, Universidade de São Paulo, São Paulo, 2009.

BRASIL. Estatuto da Cidade: Lei $n^{\circ} 10.257$, de 10 de julho de 2001. Estabelece diretrizes gerais da política urbana. Brasília, DF: Câmara dos Deputados, 2001.

CÓSTOLA, D.; ALUCCI, M. P. Aplicação de CFD Para o Cálculo de Coeficientes de Pressão Externos nas Aberturas de um Edifício. Ambiente Construído, Porto Alegre, v. 11, n. 1, p. 145-158, jan./mar. 2011.

CORBELLA, O.; YANNAS, S. Em Busca de Uma Arquitetura Sustentável Para os Trópicos: conforto ambiental. 2. ed. rev. e ampl. Rio de Janeiro: Revan, 2009.

FRANKE, J. Recommendations of the COST Action C14 on the use of CFD in Predicting Pedestrian Wind Environment. In:

INTERNATIONAL SYMPOSIUM ON COMPUTATIONAL WIND ENGINEERING, 4., Yokohama, 2006. Proceedings... Yokohama, 2006.

FRANKE, J. et al. Best Practice Guideline for the CFD Simulation of Flows in the Urban Environment. COST Office Brussels, 2007. COST 732: Quality Assurance and Improvement of Microscale Meteorological Models.

FRANKE, J. et al. Recommendations on the Use of CFD in Wind Engineering. In: BEEK, J. P. A. J. van (Ed.). INTERNATIONAL CONFERENCE ON URBAN WIND ENGINEERING AND BUILDING AERODYNAMICS: COST C14 IMPACT OF WIND AND STORM ON CITY LIFE AND BUILT ENVIRONMENT, Rhode, 2004. Proceedings... Rhode, 2004.

GOOGLE MAPS. [Mapas]. Disponível em: <http://pt.wikipedia.org/wiki/Microrregi\%C3\%A3 o_de_Bel\%C3\%A9m\#mediaviewer/File:Para_Mic ro_Belem.svg>. Acesso em: 11 nov. 2014.

GOULART, S. V. G.; LAMBERTS, R.; FIRMINO, S. Dados Climáticos Para Projeto e Avaliação Energética de Edificações Para 14 Cidades Brasileiras. 2. ed. Florianópolis: Núcleo de Pesquisa em Construção/UFSC, 1998.

LEITE, R. C. V. A Influência da Mudança nos Padrões de Ocupação do Solo Sobre a Ventilação Natural em Cidade de Clima Tropical Úmido. São Paulo, 2009. Dissertação (Mestrado em Arquitetura) - Faculdade de Arquitetura e Urbanismo. Universidade de São Paulo, São Paulo, 2009. 
NASCIMENTO, C. C. Clima e Morfologia Urbana em Belém. Belém: UFPA, NUMA, 1995.

PRATA, A. R. Impacto da Altura de Edifícios nas Condições de Ventilação Natural do Meio Urbano. São Paulo, 2005. Tese (Doutorado em Arquitetura) - Faculdade de Arquitetura e Urbanismo, Universidade de São Paulo, São Paulo, 2005.

RAMPONI, R.; BLOCKEN, B. CFD Simulation of Cross-Ventilation Flow for Different Isolated Building Configurations: validation with wind tunnel measurements and analysis of physical and numerical diffusion effects. Journal of Wind Engineering and Industrial Aerodynamics, v. 104, n. 106, p. 408-418, 2012.

REITER, S. Assessing Wind Comfort in Urban Planning. Environment and Planning: Planning and Design, v. 37, p. 857-873, 2010.

RICHARDS, P. J.; ROXEY, R. P. Appropriate Boundary Conditions for Computational Wind Engineering Model Using the k- $\varepsilon$ Turbulence Model. Journal of Wind Engineering and Industrial Aerodynamics, v. 46/47, p. 145-153, 1993.

\section{UNIVERSIDADE FEDERAL DE SANTA}

CATARINA. Programas: analysis SOL-AR.

Disponível em:

<http://www.labeee.ufsc.br/software/software>. Acesso em: 5 ago. 2013.
WIERINGA, J. Updating the Davenport Roughness Classification. Journal of Wind Engineering and Industrial Aerodynamics. v. 61, p. 357-368, 1992.

WIKIPEDIA. Belém: localização. Disponível em: <http://pt.wikipedia.org/wiki/Microrregi\%C3\%A3 o_de_Bel\%C3\%A9m\#mediaviewer/File:Para_Mic ro_Belem.svg>. Acesso em: 11 nov. 2014.

ZHANG, X. CFD Simulation of Neutral ABL flows. Ris $\varnothing$ National Laboratory for Sustainable Energy. Technical University of Denmark. Roskilde, 2009.

\section{Agradecimentos}

Os autores agradecem à Coordenação de Aperfeiçoamento de Pessoal de Nível Superior (CAPES) pelo incentivo e apoio financeiro concedido, a Companhia de Desenvolvimento e Administracao da Area Metropolitana de Belém (CODEM) pela concessão de informações valiosas à construção desse trabalho e a Universidade Federal de Viçosa (UFV). Além disso, agradeço aos professores Antônio Tibiriçá e Álvaro Tibiriçá pela orientação e colaboração imprescindível na construção dessa pesquisa.

\section{Lorena D'Arc Tork}

Departamento de Arquitetura e Urbanismo, Centro de Ciências Exatas e Tecnológicas | Universidade Federal de Viçosa | Av. P. H. Rolfs, s/n, Campus Universitário | Vicosa - MG - Brasil | CEP 36570-000 | Tel.: (31) 3899-1964 | E-mail: lorenatork@gmail.com

\section{Antônio Cleber Gonçalves Tibiriçá}

Departamento de Arquitetura e Urbanismo, Centro de Ciências Exatas e Tecnológicas | Universidade Federal de Viçosa | E-mail: tibirica@ufv.br

Álvaro Messias Bigonha Tibiriçá

Departamento de Engenharia de Produção e Mecânica | Universidade Federal de Viçosa | Tel.: (31) 3899-4097 |

E-mail: alvaro.tibirica@ufv.br

\section{Revista Ambiente Construído}

Associação Nacional de Tecnologia do Ambiente Construído

Av. Osvaldo Aranha, $99-3^{\circ}$ andar, Centro

Porto Alegre - RS - Brasil

CEP $90035-190$

Telefone: +55 (51) 3308-4084

Fax: +55 (51) 3308-4054

www.seer.ufrgs.br/ambienteconstruido

E-mail: ambienteconstruido@ufrgs.br 